Chapter 14

\title{
Liver Transplantation and \\ Endoscopic Management of Bile Duct Complications
}

\author{
Bassam Abu-Wasel, Paul D. Renfrew and \\ Michele Molinari \\ Additional information is available at the end of the chapter \\ http://dx.doi.org/10.5772/52630
}

\section{Introduction}

The first human liver transplant (LT) was performed in 1963 by Starzl and colleagues at the University of Colorado in Denver [1]. Since then, LT has become a life-saving procedure for patients with irreversible chronic and acute liver failure (ALF) [2-4].Only a few cases were performed during the following 15-year as the results were not satisfactory and 1-year survival rate was only $30 \%$ due to early rejection and graft failure. In the late 1970s and early 1980s, the implementation of cyclosporine-based immunosuppression led to the doubling of the 1-year survival rate and LT, from an experimental procedure, became standard of care for patients with end stage liver disease (ESLD) [5]. In the last two decades, significant advances occurred in all aspects of LT, including donor management, recipient selection, surgical techniques, immunosuppression, and postoperative care. These changes have resulted in considerable improvements in the care provided to LT recipients, and the current overall 1-year survival is now in excess of $85 \%$, with 5 - and 10 -year survival ranging between $70-85 \%$ and $60-70 \%$, respectively [6-9]. Despite all these major advances, biliary complications after LT still represent a common and challenging problem for both patients and their caregivers.

The main aim of this chapter is to inform the reader on the current indications and contraindications for LT, the risk factors associated with postoperative biliary complications and to evaluate the endoscopic techniques currently available for the diagnosis and treatment of these patients.

\section{Epidemiology of liver failure}

Liver disease is a common and broad definition used to describe any acute and chronic liver disorders that includes: 
- Steatosis

- Fibrosis

- Cirrhosis

- Acute and chronic hepatitis (viral, metabolic, autoimmune etc.)

- Primary hepatic malignancies (hepatocellular carcinoma and cholangiocarcinoma)

ESLD encompasses all those clinical conditions characterized by the irreversible deterioration of the hepatic function and is responsible for over two million outpatient visits and over 750,000 hospitalizations per year only in the United States (US) [10]. Currently, chronic liver disease and cirrhosis are among the tenth leading causes of death, and the annual number of fatalities has remained essentially unchanged (25,000 per year) over the past two decades (Table 1).Every year in the US, over 40,000 patients develop ESLD and approximately 2,000 ALF [11]. Unfortunately, only 5,000-6,000 will undergo LT [12] and the current mismatch between the number of available grafts and the number of patients waiting for LT is responsible for 5 to $10 \%$ yearly mortality rate.

\begin{tabular}{|c|c|}
\hline Primary Disease & $\%$ of Mortality \\
\hline Heart disease & 31.0 \\
\hline Malignant neoplasms & 23.2 \\
\hline Cerebrovascular disease & 6.8 \\
\hline COPD & 4.8 \\
\hline Trauma & 4.2 \\
\hline Pneumonia and influenza & 3.9 \\
\hline Diabetes & 2.8 \\
\hline Suicide & 1.3 \\
\hline Kidney diseases & 1.1 \\
\hline Chronic liver disease or cirrhosis & 1.1 \\
\hline
\end{tabular}

Data from Murphy S. Deaths: final data for 1998. National vital statistics reports. Hyattsville, MD: National Center for Health Statistics, 2000, Vol. 48.

Table 1. The ten leading causes of deaths in United States.

\section{Indications for liver transplantation}

LT is indicated for all the clinical conditions summarized in Table 2. Because LT is the only cure for ESLD, patients who develop signs of liver decompensation should be referred to transplant centers before their conditions deteriorate to a point when LT is no longer feasible (Table 3). 


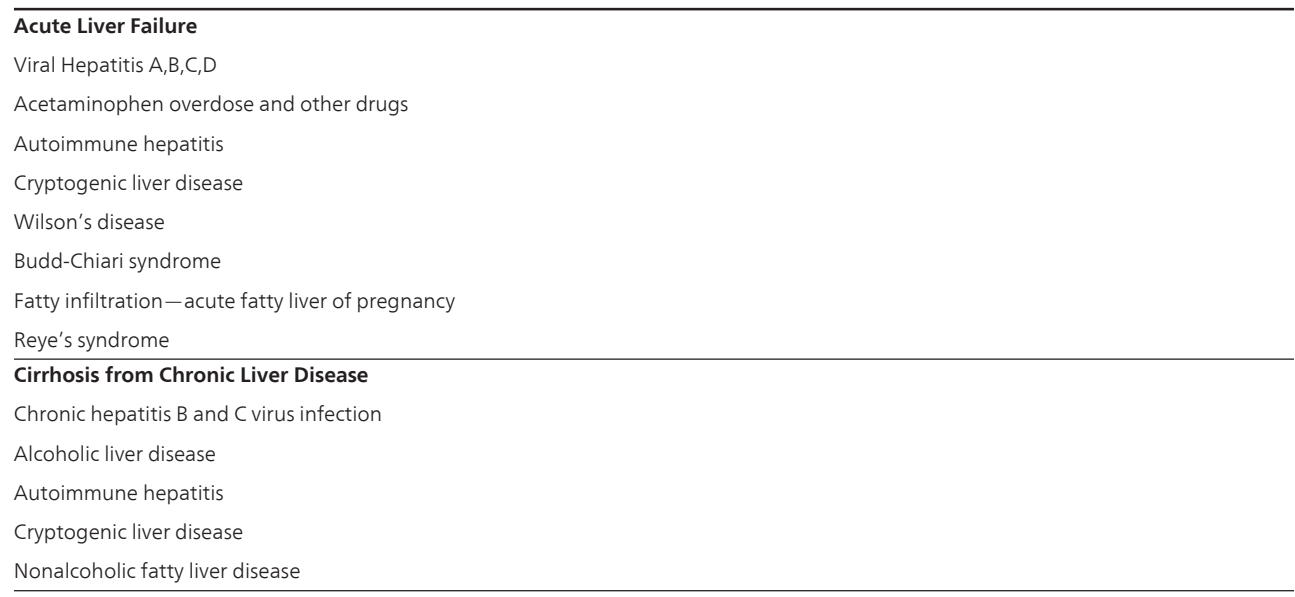

\section{Metabolic Liver Disease}

Wilson's disease

Hereditary hemochromatosis

Alpha-1 antitrypsin deficiency

Glycogen storage disease

Cystic fibrosis

Glycogen storage disease I and IV

Crigler-Najjar syndrome

Galactosemia

Type 1 hyperoxaluria

Familial homozygous hypercholesterolemia

Hemophilia A and B

\section{Vascular Diseases}

Budd-Chiari syndrome

Veno-occlusive disease

\section{Cholestatic Liver Diseases}

Primary biliary cirrhosis

Primary sclerosing cholangitis

Secondary biliary cirrhosis

Biliary atresia

Alagille syndrome

Byler's disease

\section{Miscellaneous}

Adult polycystic liver disease

Nodular regenerative hyperplasia

Caroli's disease

Severe graft-versus-host disease

Amyloidosis

Sarcoidosis

Hepatic trauma

Table 2. Main causes of irreversible liver failure. 


\begin{tabular}{l}
\hline Ascites \\
\hline Coagulopathy \\
\hline Encephalopathy \\
\hline Jaundice \\
\hline Cachexia \\
\hline Hepatorenal Syndrome \\
\hline Pulmonary Hypertension \\
\hline Persistent and intractable pruritus
\end{tabular}

Table 3. Some of the most common clinical manifestations of liver failure.

Cirrhosis is the main indication in the adult population and it accounts for more than $80 \%$ of LTs performed in the world. Other frequent indications in the US are: hepatitis C $(21 \%)$, alcoholic liver disease $(16 \%)$, cholestatic liver disease including primary biliary cirrhosis and sclerosing cholangitis (17\%). Less frequent indications include: chronic hepatitis (hepatitis B, autoimmune hepatitis), metabolic disease (e.g. Wilson's disease, nonalcoholic steatohepatitis), fulminant hepatic failure, and non-metastatic HCC [13].

In the pediatric population the most frequent indication for LT includes biliary atresia and congenital metabolic diseases.

\subsection{Acute liver failure}

ALF accounts for $5 \%$ of all LT in the US. The most common causes are: toxins or drug induced liver injury (e.g., acetaminophen), viral hepatitis, or, less commonly, autoimmune hepatitis or Wilson disease [14-16]. In approximately 15-17\% there are no identifiable causes [17].

\subsection{Hepatocellular carcinoma}

Most transplant centers would perform LT for patients with unresectable HCCs who satisfy the Milan criteria (absence of metastatic disease and one of the following two conditions: a single lesion with maximum diameter equal or smaller than $5 \mathrm{~cm}$ in diameter or three or fewer lesions, the largest of which measures up to $3 \mathrm{~cm}$ in diameter) [18]. The 5-year survival rate in this setting is $75-80 \%$, which is comparable to survival rates of patients undergoing LT for benign conditions. At the University of California, San Francisco (UCSF), LT has been advocated for patients without extra-hepatic disease and affected by single tumors measuring up to $6.5 \mathrm{~cm}$ or by 3 or fewer lesions with the largest being equal or smaller than $4.5 \mathrm{~cm}$ and with a total tumor burden of $8 \mathrm{~cm}$ or less with similar short and long term outcomes to patients within the Milan criteria [19-22]. 


\subsection{Cholangiocarcinoma}

In the past, all patients with cholangiocarcinoma (CC) were thought to be poor candidates for LT due to their high rate of recurrent disease and poor survival. However, at the Mayo Clinic in Minnesota, a novel therapeutic protocol for unresectable hilar CC or CC arising in the setting of PSC combines an intensive protocol that uses neo-adjuvant chemo and radiation therapy prior to LT. Patients treated at that centre have shown excellent 1-year survival up to $82 \%$ and comparable to patients undergoing LT for other causes $[16,21]$. On the other hand, patients with intrahepatic CC appear to be still poor candidates due to their poor prognosis even if treated with neo-adjuvant chemo-radiation therapy [23].

\section{Contraindications to liver transplantation}

Contraindications to LT can be divided in two main groups: relative contraindications and absolute contraindications. Relative contraindications are all those conditions that prevent optimal outcomes, and therefore, should be corrected whenever possible prior to transplantation (Table 4) [ $\left.\begin{array}{lll}1 & 11 & 24\end{array}\right]$. Absolute contraindications, instead, are not reversible and lead to unsatisfactory outcomes and their presence should prevent LT if recognized in time (Table 5) [3 5].

- HIV/AIDS

- Age "/> 65 years

- Severe malnutrition

- Other irreversible organ failure

- Previous major upper abdominal surgeries

- Poor functional status

- Previous history of poor compliance

Table 4. Relative contraindications to LT.

- Severe cardiopulmonary disease

- Irreversible cerebral injury

- Sepsis or active infection

- Most of the extra-hepatic malignancies except for non-melanoma skin cancer

- Major vascular thrombosis of the arterial or venous system preventing successful arterial or venous reconstructions

- Active alcohol or drug abuse

- Sever psychological conditions

Table 5. Absolute contraindications to LT. 


\section{Pediatric liver transplantation}

Pediatric LT is one of the most successful transplant procedures [25]. The 1-year patient survival rate is $83 \%$ to $91 \%$, depending on the age of the child at the time of surgery [26].Five-year patient survival is also excellent, ranging from 82 to $84 \%$. The number of pediatric LTs per year has remained steady in the last decade, averaging approximately 600 per year in the US. About $55 \%$ of these transplants are for end-stage chronic liver disease, the majority of these due to biliary atresia; about $25 \%$ are for metabolic liver diseases, $10 \%$ for ALF, and 5\% for hepatic malignancies [27 28]. Underlying diagnoses of children undergoing LT are presented in Table 6. In pediatric LT, there are very few absolute contraindications. These include conditions in which LT is futile and will not improve the overall survival or quality of life, and this list of conditions has shortened dramatically over the years (Table 7).

\section{Diagnosis}

Frequency (\%)

Cholestatic liver disease

Biliary atresia

Others: Alagille syndrome, sclerosing cholangitis, progressive familial intrahepatic

cholestasis

Fulminant hepatic failure

Metabolic liver disease

Primary hepatic disease:

Wilson disease, a-1-antitrypsin deficiency, tyrosinemia, cystic fibrosis

Primarily nonhepatic disease:

ornithine transcarbamylase deficiency, primary hyperoxaluria type 1, organic

academia

Liver tumors

Data from Ng VL, Fecteau A, Shepherd R, et al. Outcomes of 5-year survivors of pediatric liver transplantation: report on 461 children from a North American multicenter registry. Pediatrics 2008;122(6):e1128-35.

Table 6. Underlying diagnoses of children undergoing liver transplantation. 


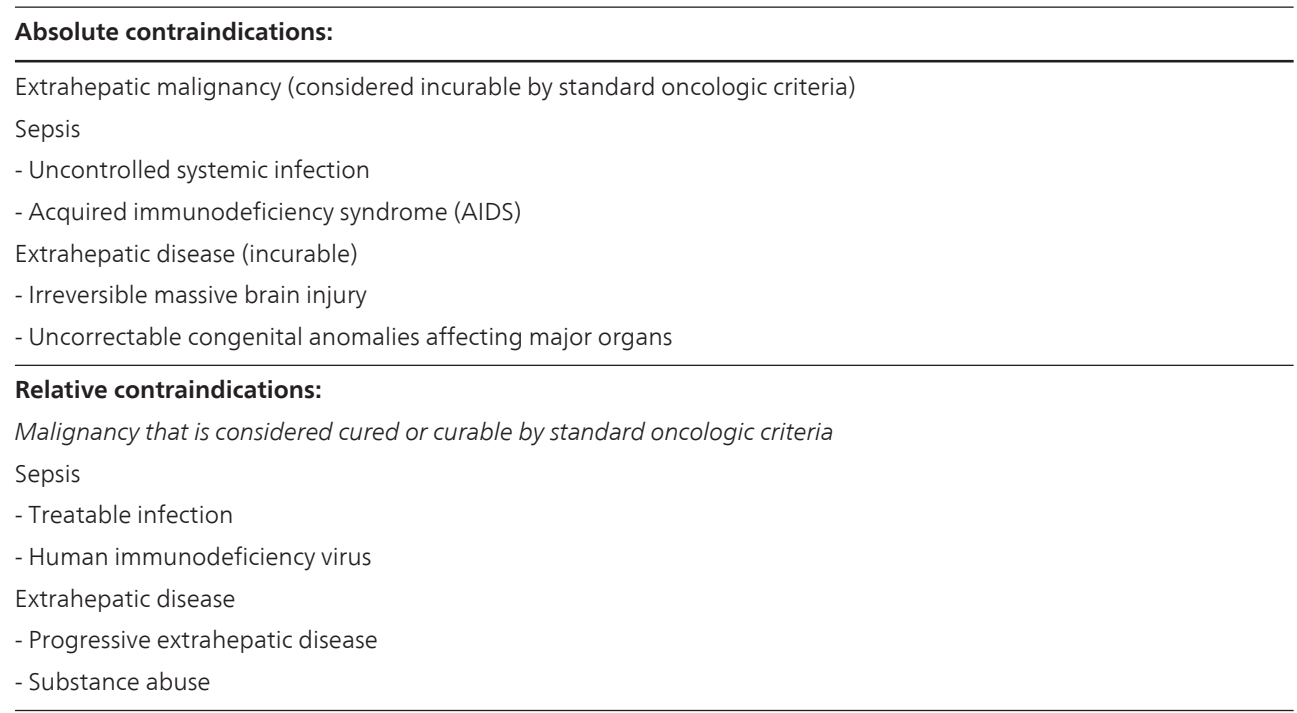

Table 7. Contraindications to pediatric liver transplantation.

\section{Cadaveric graft allocation}

To optimize the distribution of cadaveric grafts to patients who are in most need, the United Network for Organ Sharing (UNOS) in the US has proposed the use of the Model for End-stage Liver Disease (MELD) and Pediatric End-stage Liver Disease (PELD), which are numerical scales reflecting the degree of organ dysfunction [29]. These scores are predictive of each patient's risk of dying while waiting for a LT in 3 months period. The MELD score, used for patients aged 12 years and older, is based on serum bilirubin levels, international normalized ratio (INR), and creatinine. The PELD score, in addition to the serum levels of bilirubin, INR and albumin includes also the presence of growth failure and patients' age, which are all associated with the mortality risk in children with liver failure. Alone, these scores are not sufficient for the final allocation of liver grafts as other important factors need to be carefully evaluated such as: the compatibility between the donor's and the recipients' blood groups, the size of the graft in relation to the body size of the recipient, and finally, the fact that in some circumstances available grafts are prioritized for individuals who suffers from ALF.

\section{Surgical technical aspects of liver transplantation}

During LT, biliary reconstruction is the final step before the abdominal wall is closed and patients leave the operating room (Figure $1-A, B, C, D$ ). Biliary anastomoses are performed after all the vascular anastomoses have been successfully completed and satisfactory hemostasis is reached. 


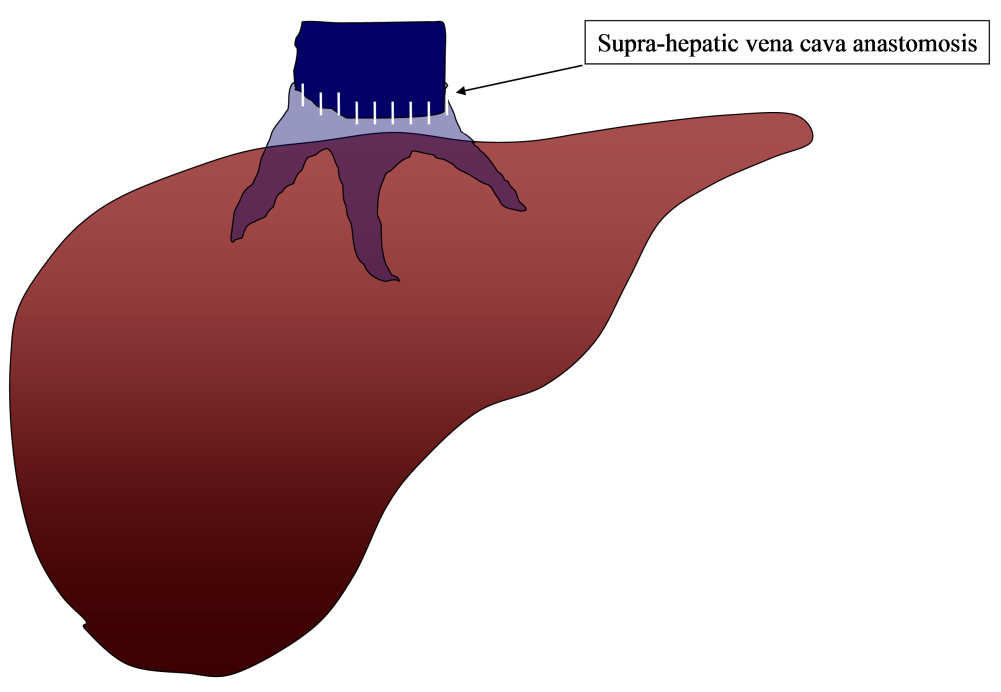

Figure 1A

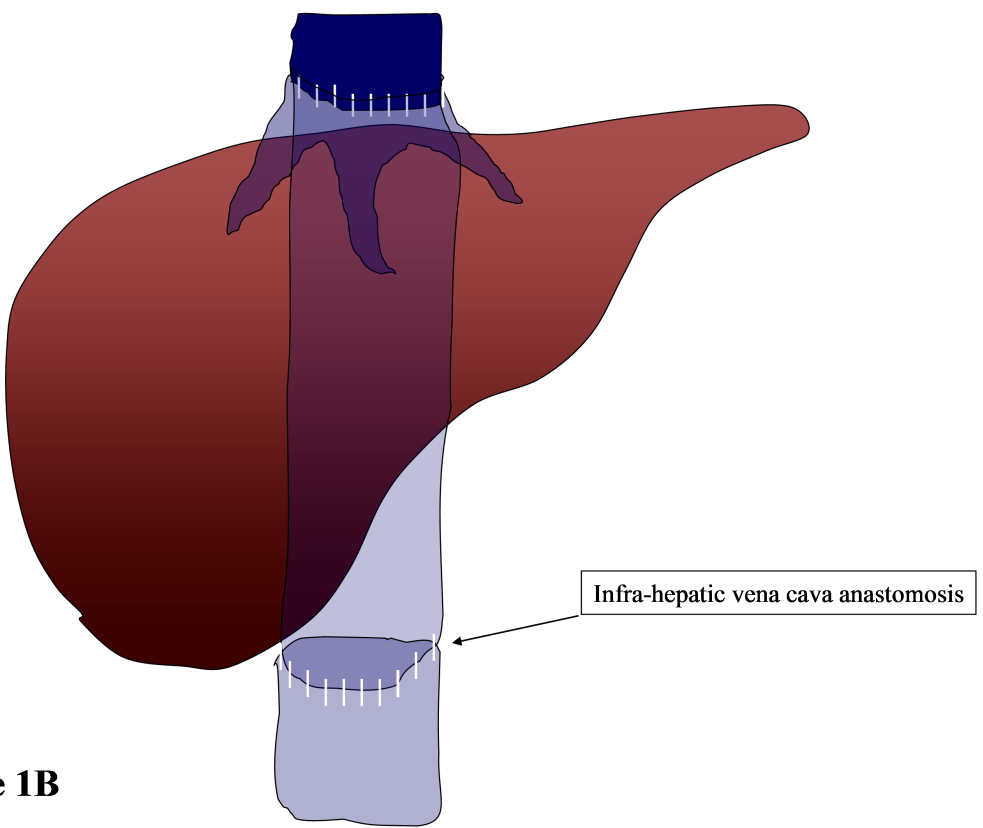

Figure 1B 

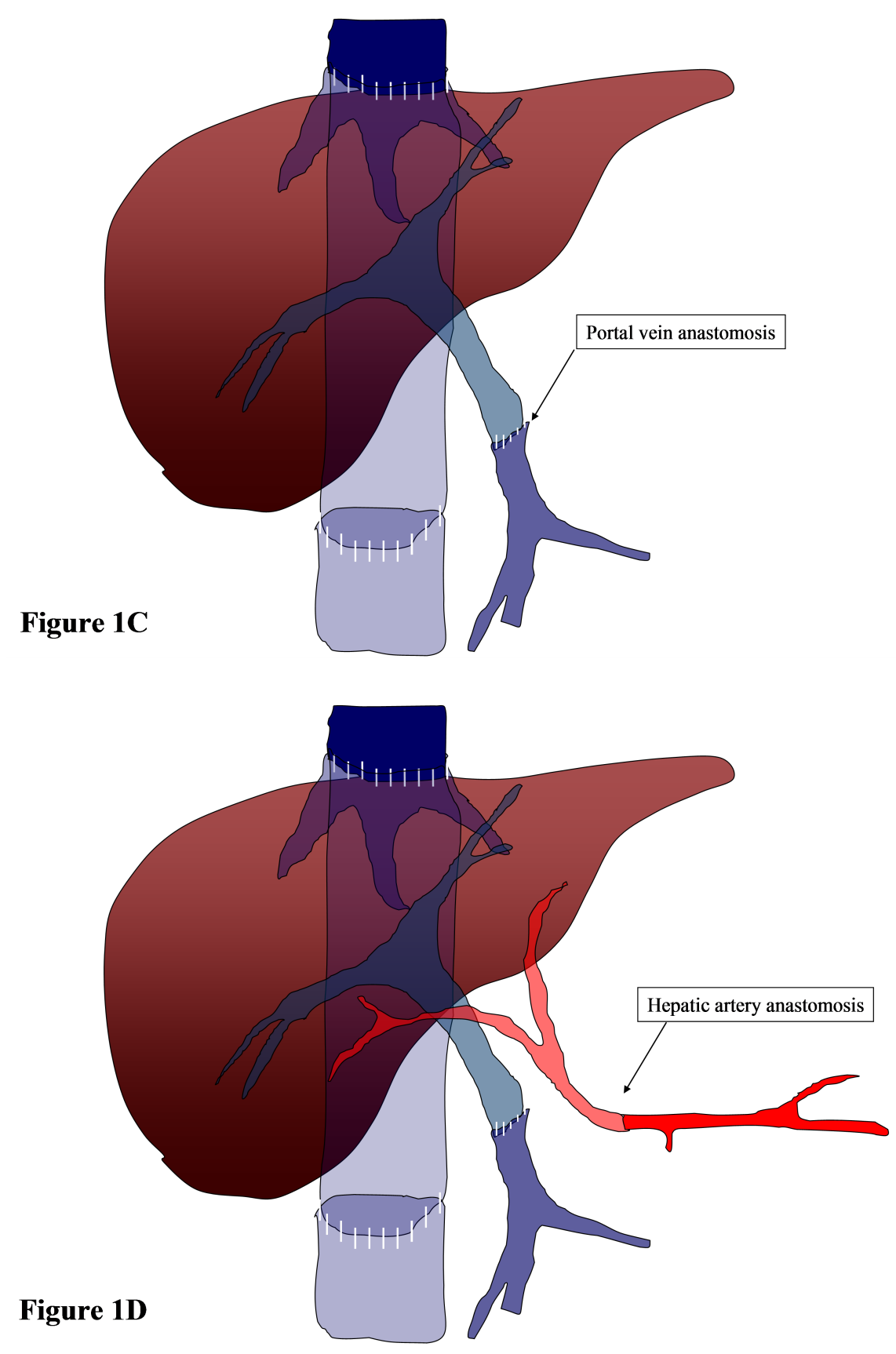


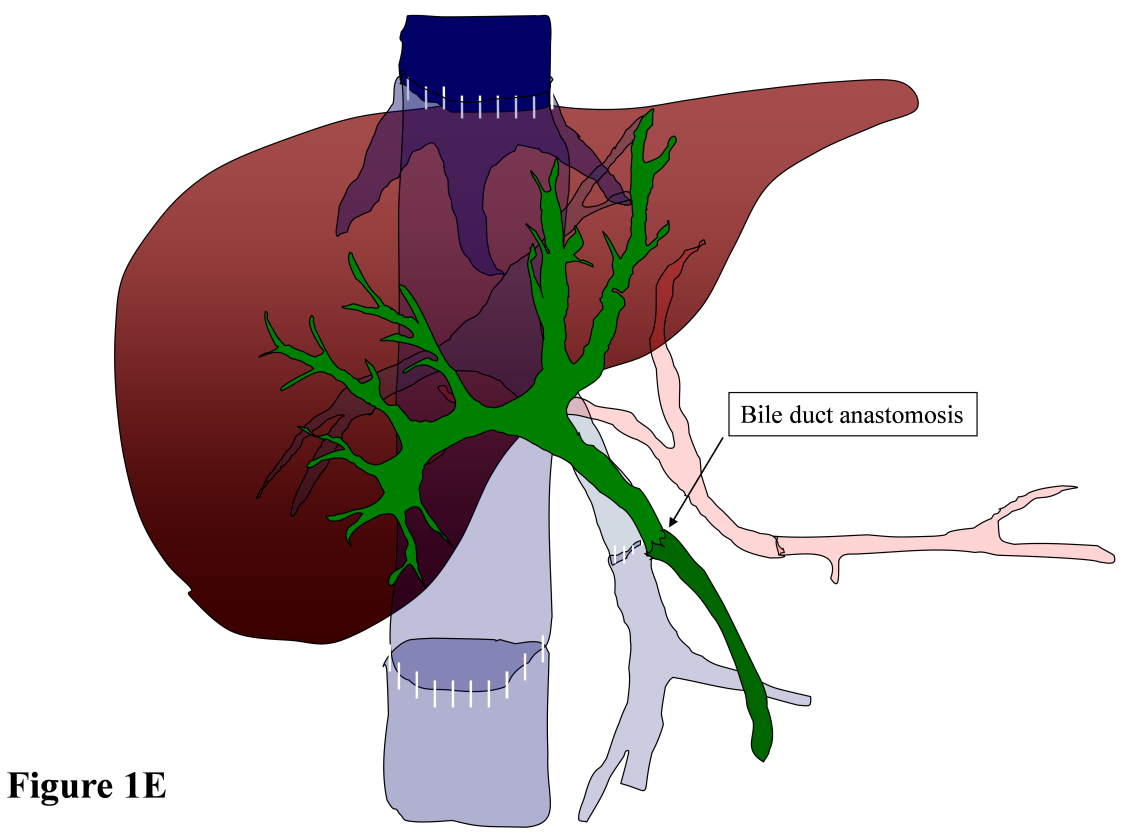

Figure 1. Temporal representation of all the necessary anastomoses performed during an orthotopic full organ LT with interposition of the donor's vena cava. After the native liver is mobilized and removed from the recipients' abdominal cavity, the liver graft is positioned in the same location (orthotopic liver transplantation) and anastomosed to the recipient's vascular and biliary structures. The first anastomosis performed is the supra-hepatic vena cava (Figure $1 \mathrm{~A})$, the second is the infrahepatic vena cava (Figure 1B), the third is the portal vein anastomosis (Figure 1C). After the portal vein anastomosis is completed, the liver graft is reperfused. The last vascular anastomosis is represented by the hepatic artery reconstruction (Figure 1D) followed by the biliary duct anastomosis (Figure 1E).

An end-to-end duct-to-duct anastomosis is the reconstruction of choice in patients with healthy native bile ducts of suitable caliber [30] as it reconstitutes the physiological hepato-enteric biliary cycle (Figure 1E). This technique is simpler and faster than the creation of biliary-enteric anastomoses (Figure 2A) and, when indicated, the biliary system can be investigated and treated endoscopically by retrograde cholangiography (ERCP). A side-to-side variant of the duct-toduct anastomosis has also been used by some groups with similar good results (Figure 2B) [31, 32]. On the other hand, the surgical technique that used the gallbladder as a conduit between the donor's and the recipient's bile ducts or intestine, has been abandoned because of the associated bile stasis and stone formation causing frequent episodes of cholangitis, which lead to surgical revisions and overall inferior outcomes(Figure 2C) [33, 34, 35]. Roux-en-Y hepaticojejunostomy (Figure 2A) is utilized in cases of preexisting disease of the native biliary tract observed when patients are affected by primary sclerosing cholangitis or biliary atresia in the pediatric population. In addition, this technique is often used when there is disparity in size between the donor's and the recipient's bile ducts, when the common bile duct is very small and at risk of developing strictures at the anastomotic site and it is usually the preferred technique 
for the biliary reconstruction during retransplantations because of the inadequate length of the native biliary system [36, 37]. In the early years of living-donor LT and split LT, Roux-en-Y hepatico-jejunostomy was also the standard biliary reconstructive technique. With growing experience of the surgical technique and meticulous attention in preserving the blood supply around the native common bile duct [38,39], duct-to-duct anastomosis has become the preferred reconstruction technique even during right lobe living-donor transplantation in the adult population [40,41], as well during the right lobe split transplant [42, 43]. Initially, duct-to-duct anastomosis created during the right lobe living-donor transplants was only performed when a single donor duct was available. More recently, the use of the recipient right and left hepatic ducts, as well as the cystic duct has been reported by several authors even when facing the need of creating multiple biliary anastomoses [44, 45]. Alternatively, both duct-to-duct and bilioenteric reconstructions may also be used simultaneously in the same patient.

Left biliary-jejunostomy remains the method of choice for biliary reconstruction when using left lateral segment grafts during split livers or living related transplantations [46, 47] although, even in these circumstances, a duct-to-duct anastomosis has been recommended by some authors [48, 49].

\section{Biliary complications after liver transplantation}

Biliary complications after LTare relatively frequent and occur in 5-25\% of patients and represent one of the major causes of morbidity and even mortality in this group of patients [50,51,52, $53,54,55]$.The complication rate of the biliary system varies according to the surgical techniques and nature of the graft. Biliary complications are less frequent in patients undergoing LT with the use of full size grafts (5-15\%) while the incidence of biliary complications in living donor, split or reduced size grafts is much more significant and ranges between 15 to $30 \%$ [56, 57].

Biliary leaks and strictures occurring at the anastomotic site are the most common biliary complications. Other less frequent adverse events are: sphincter of Oddi dysfunction, hemobilia, biliary obstruction from cystic duct mucoceles, stones, sludge or formation of biliary duct casts that will be discussed later on in this chapter [50, 51, 58].

\section{Temporal presentation of biliary complications}

After LT, complications of the biliary tract can occur both in the immediate perioperative period, as well as several months or years after the procedure.

Conventionally, biliary complications are divided into three main categories:

- Early Complications (observed within 30 days after LT)

- Delayed Complications (observed during the second and third month after LT)

- Late Complications (observed after 3 months post LT) 


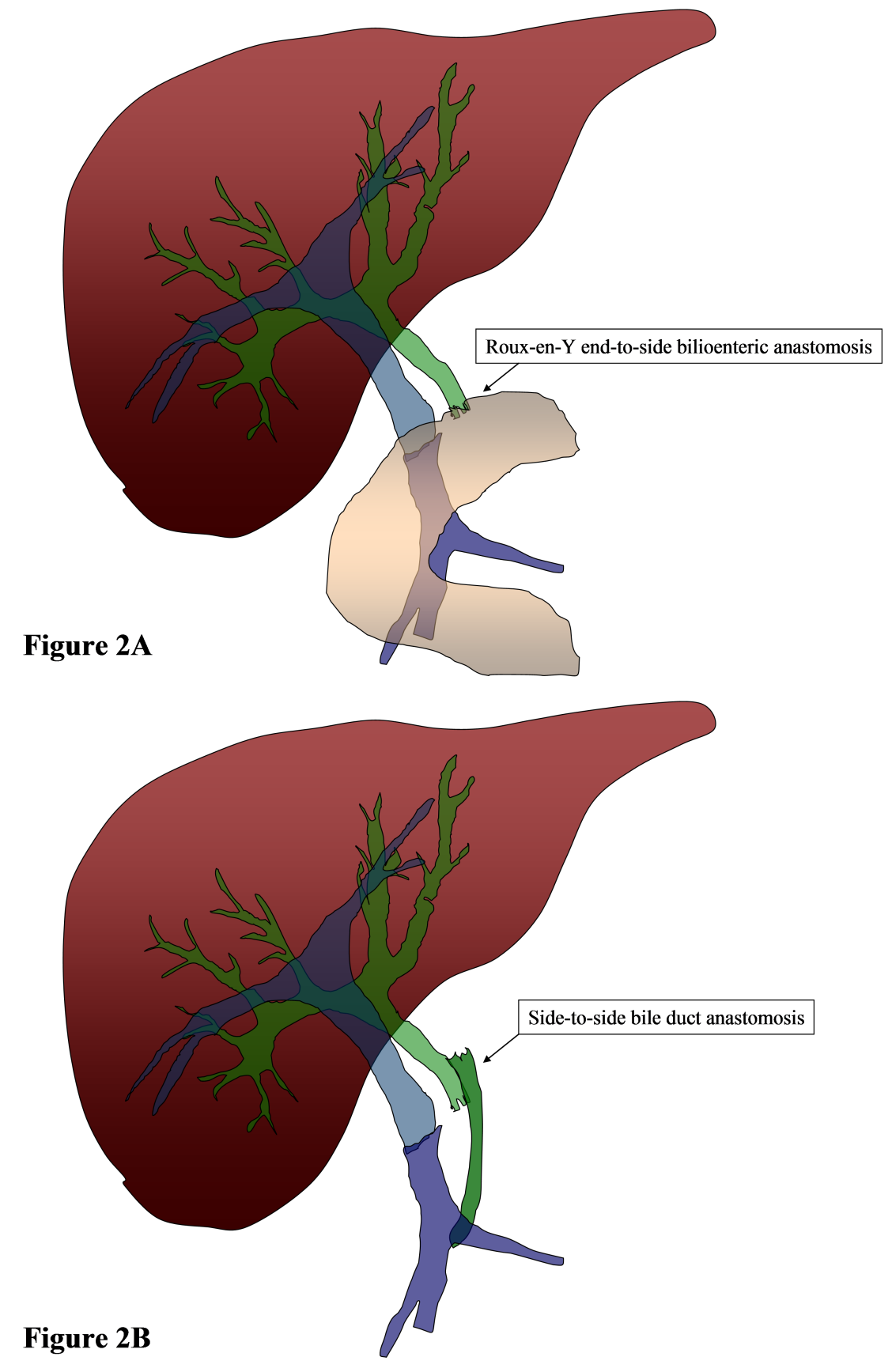




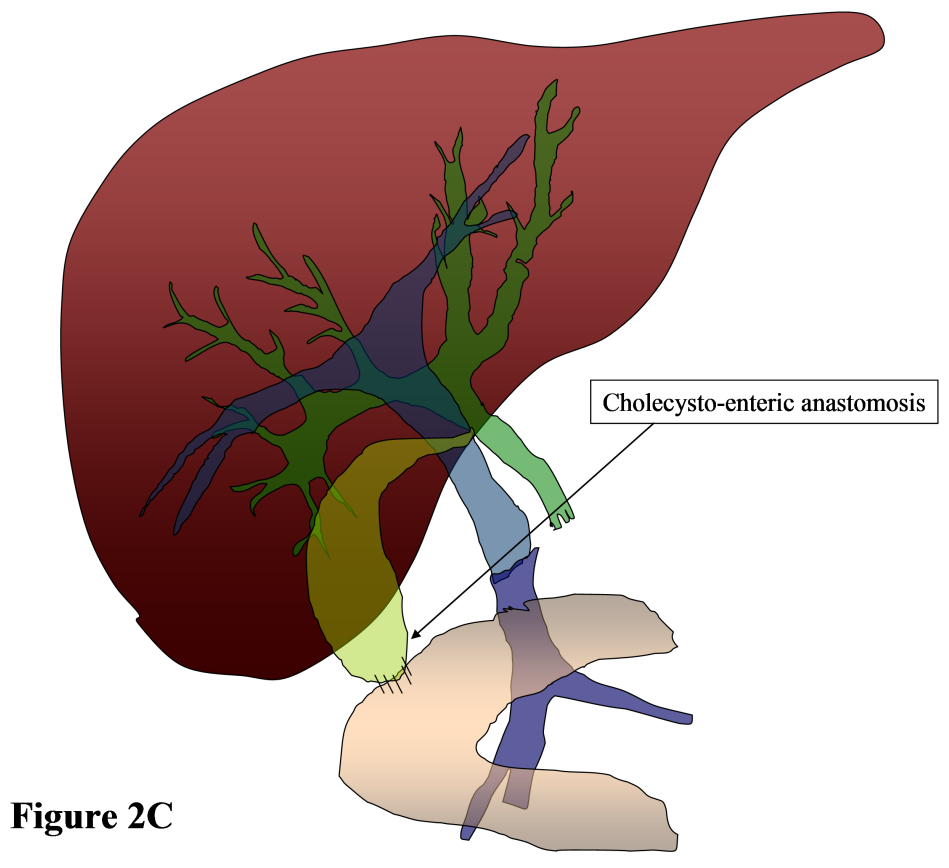

Figure 2. Graphical representation of the most common biliary reconstructions performed in liver transplantation. The most common technique is the reconstruction with an end-to-end bile duct anastomosis as represented in Figure $1 \mathrm{E}$. With this technique, the two end of the donor's and the recipient's common bile ducts are anastomosed together allowing the bile to flow in a very physiologic way. Less frequently, the bile duct reconstruction is obtained by creating a Roux-en-Y bilioenteric anastomosis (Figure 2A) where the common bile duct of the donor is anastomosed to the antimesenteric wall of a loop of small intestine of the recipient, or by creating a side-to-side bile duct anastomosis (Figure 2B). In the past, a cholecysto-enteric anastomosis was often used to drain the bile but this technique has been almost completely abandoned (Figure 2C).

\section{Risk factors of biliary complications}

Several factors have been identified as predisposing conditions for the development of biliary complications in LT recipients. Among them the most common are: hepatic artery thrombosis, thermal and ischemic injury to the peri-biliary duct tissues, inferior quality of the liver graft, prolonged cold and warm ischemia time, blood type incompatibility between the donor and the recipient, infections and tension between the two ends of the biliary anastomosis.

\subsection{Hepatic artery thrombosis or stenosis}

The hepatic artery plays an important role in the blood supply of the bile duct and insufficient arterial blood flow is responsible for both acute and chronic ischemia of the biliary system. Acute ischemia can lead to anastomotic disruptions and subsequent biliary leaks in the 
immediate postoperative period or delayed strictures that can occur at the level of the anastomosis or in other parts of the intra and extra-hepatic ducts.

\subsection{Technical factors}

During surgery the most common technical factors that can result in biliary complications are: the excessive dissection of the periductal tissue during the procurement or during the mobilization of the native liver,and the excessive use of electrocautery to control bleeding from the peribiliary tissues. Another important risk factor for biliary anastomotic failures is the presence of tension between the two ends of the biliary anastomosis that can lead to an incomplete seal and subsequently to leaks and formation of peri-hepatic absesses.

\subsection{Quality of the grafts and cold and warm ischemia times}

Biliary complications are more frequent in recipients of grafts procured from donors after cardiac death who have an increased risk of experiencing insufficient organ perfusion or suboptimal oxigenation of the liver. This undesired warm ischemia time has been considered one of the most important risk factors for biliary complications that frequently affect recipients of livers from donors after cardiac death. In addition, biliary complications have been encountered more frequently after the use of grafts from older donors, grafts with steatosis, and in all those circumstances where the grafts experience suboptimal cold storage and prolonged cold or warm ischemia [59].

\subsection{Placement of T-tubes}

In the past, T-tubes were placed routinely in all patients undergoing LT to monitor the production of bile as a proxy for early graft function and, theoretically, to prevent anastomotic strictures. The role of T-tubes in LT, in the era of endoscopic therapy, is much less apparent and they have been almost unanimously abandoned. Comparative studies between post-LT patients with and without T-tubes indicate that routine T-tube placement is associated with a higher incidence of biliary complications including bile leaks and cholangitis [60,61]. A recent meta-analysis including more than 1,000 patients indicated that those patients without a T-tube had better outcomes compared with those with a T-tube, including fewer episodes of cholangitis and fewer episodes of peritonitis [62].

\subsection{Biliary reconstruction}

The most common technique used for the reconstruction of the biliary system in patients undergoing cadaveric LT is the duct-to-duct choledocho-choledochostomy anastomosis (Figure $3 \mathrm{~A}$ ). When this technique is not feasible, most patients undergo a Roux-en-Y choledochojejunostomy (Figure 3B). Duct-to-duct choledochocholedochostomy has the advantage of being easier and quicker to perform, it is more physiological and prevents enteric reflux into the bile ducts, and it has also the advantage of allowing easier access to the biliay system by endoscopic means [63]. Several studies have shown that the risk of biliary complications with the Roux-en-Y reconstruction is similar, or only slightly higher compared with the duct-toduct anastomosis [51, 64]. 


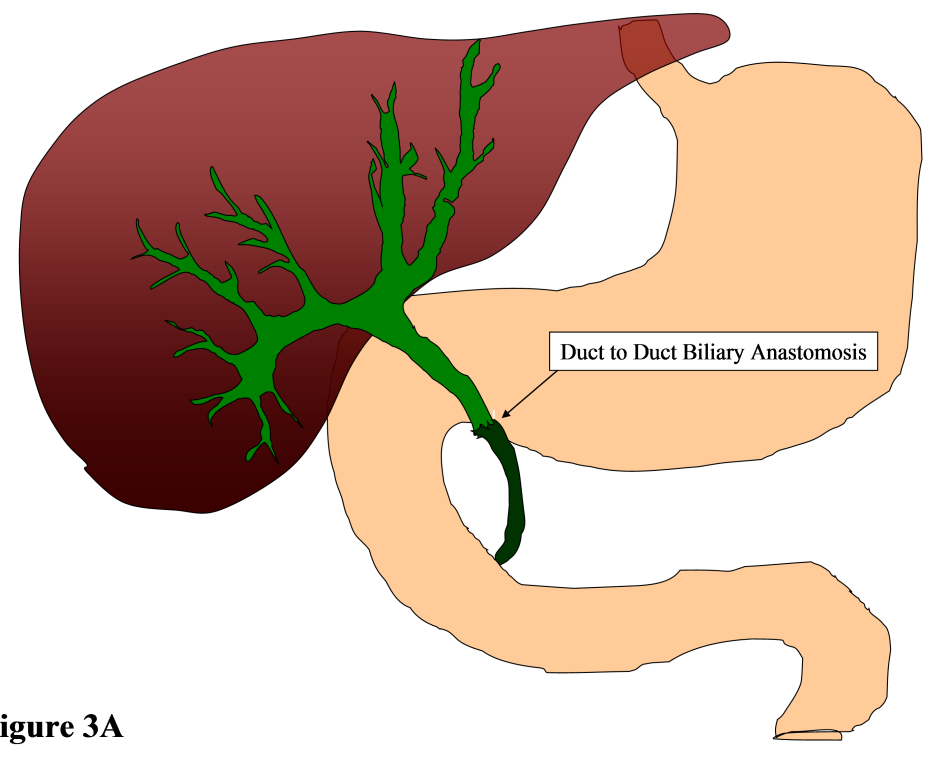

Figure 3A

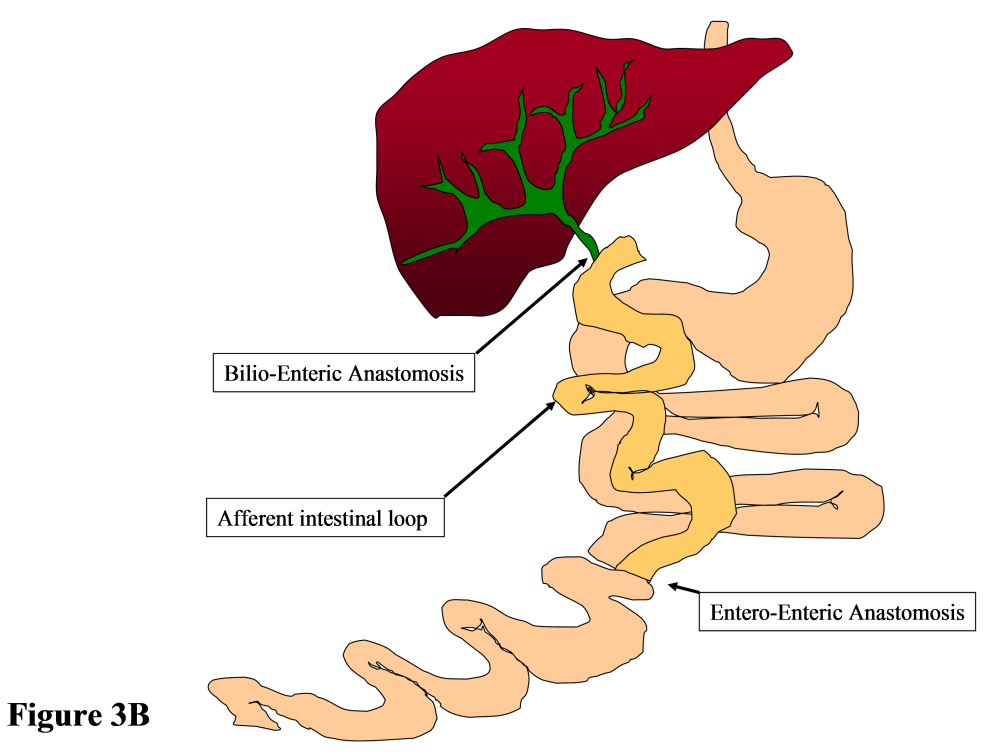

Figure 3. Graphical representation of the two most common biliary reconstruction after cadaveric liver treansplantation. Figure 3A represent the classical duct-to-duct reconstruction where the donor's bile duct is anastomosed to the recipient bile duct. This anastomosis has the advantage of being less time-consuming than the biliary-enteric anastomosis (Figure 3B) and it allows a physiological flow of bile into the duodenum. Another significant advantage is that the biliary system of patients undergoing a duct-to-duct anastomosis can be reached by endoscopic means. This allows the insertion of stents or dilatation when biliary leaks or stricture develop. 


\subsection{Other risk factors}

Several other predisposing factors for biliary complications have been identified. Among them, the most frequent are: pre-LT cytomegalovirus infection [65, 66], LT performed between donors and recipients with $\mathrm{ABO}$ blood group incompatibility, the diagnosis of primary sclerosing cholangitis as the primary indication for LT and intra-abdominal infections in the perioperative period.

\section{Clinical presentation and diagnosis of biliary complications}

The clinical presentations of biliary complications after LT can be challenging as they depend on the time of occurrence, degree of severity and patients' characteristics. Elevation of the recipient's white blood count, fever, abdominal pain, ileus and cholestasis are common findings in patients who develop early biliary complications. Often, immunosuppressed patients can be asymptomatic for a relatively long period of time before they manifest any clinical condition that can lead to the appropriate diagnosis. In asymptomatic patients, suspicion of a biliary complication should occur in the presence of any unexplained elevation of serum aminotransferases, total bilirubin, alkaline phosphatase, and gamma-glutamyltransferase levels in the absence of acute rejection. Biliary leaks are often diagnosed as fluid collections on abdominal imaging performed for unrelated reasons.

\section{Non-invasive diagnostic modalities}

Noninvasive radiologic investigations usually begin with a trans-abdominal ultrasound (US), which is often used in combination with Doppler examination of the flow characteristics of the hepatic artery, portal and hepatic veins. Triphasic contrast computed tomography (CT), magnetic resonance cholangiopancreatography (MRCP) and nuclear medicine HIDA scan are usually complementary investigations to the original abdominal US. Further diagnostic steps in the evaluation of these patients depend upon the initial findings. Among them, the most frequently performed are: ERCP and percutaneous transhepatic cholangiography (PTC).

\section{Invasive diagnostic modalities}

\subsection{Endoscopic retrograde cholangiopancreatography}

ERCP plays a primary role in the management of biliary complications after LT. Despite the lack of large randomized trials, ERCP has become the procedure of choice for all LT patients with their biliary tract accessible to endoscopic manipulation. Post-ERCP complications are similar to the general population and include: pancreatitis, bleeding, infec- 
tions and perforation. Overall, the complication rate in this population ranges between $2 \%$ to $6 \%[67,68,69,70,71,72]$ confirming that ERCP is relatively safe even in this subset of immunocompromised patients who often have persistent thrombocytopenia due to hyperspenism and transient coagulative dysfunction.

\subsection{Percutaneous transhepatic cholangiography}

PTC and percutaneous transhepatic biliary drainage (PTBD) are necessary when ERCP can not be performed or when it has failed. The most frequent indication for PTC in post LT patients is the presence of a Roux-en- $Y$ biliary enteric anastomosis that prevents the access to the biliary duct by endoscopic approach. In comparison to ERCP, PTC is more hazardous in the presence of thrombocytopenia or coagulopathy and it can be technically very challenging when the intra-hepatic biliary ducts are not dilated, for example in the presence of a bile duct anastomotic leak. On the other hand, anastomotic strictures are responsible for the dilatation of the biliary ducts, making PTC easier and safer. The determination of whether to perform ERCP or PTC depends upon anatomic considerations, the diameter of the donor biliary tree, and the overall morbidity related to issues of sedation and coagulation status [73, 74].

\section{Biliary stents}

Endoscopic biliary stents were first introduced in 1979 [75] primarily for the palliation of malignant strictures. Until then, surgery (such as choledochojejunostomy, choledochoduodenostomy, and cholecysto-jejunostomy) had been the mainstay of treatment. Initially, interventional radiologists developed percutaneous techniques that allowed the placement of external biliary drainages. Subsequently, the introduction of new methods allowed the internalization of biliary drains that immediately became more attractive as patients did not suffer from significant fluid losses, malnutrition due to decreased intestinal absorption of lipids and fat-soluble vitamins (e.g. vitamin K, A, D, E). Plastic stents (Figure 4A and $4 \mathrm{~B}$ ) have a median duration of 3-4 months as they are subject to obstruction due to deposition of debris in their lumen and subsequent risk of ascending cholangitis. The limited long-term patency rate of plastic stents fuelled the development of metal stents that are significantly larger in diameter and have lower propensity to obstruct. Nowadays, metal stents are available in various designs. The designs differ from one another in the diameter of the expanded stent, diameter of the delivery system, length of the stent, and wall thickness [76]. Metal stents were conventionally of two types (ie, balloonmouthed or self-expanding); however, nowadays self-expandable metallic stents (SEMS) (Figure 4C) are more commonly used, with balloon-mouthed stents having become somewhat archaic. 


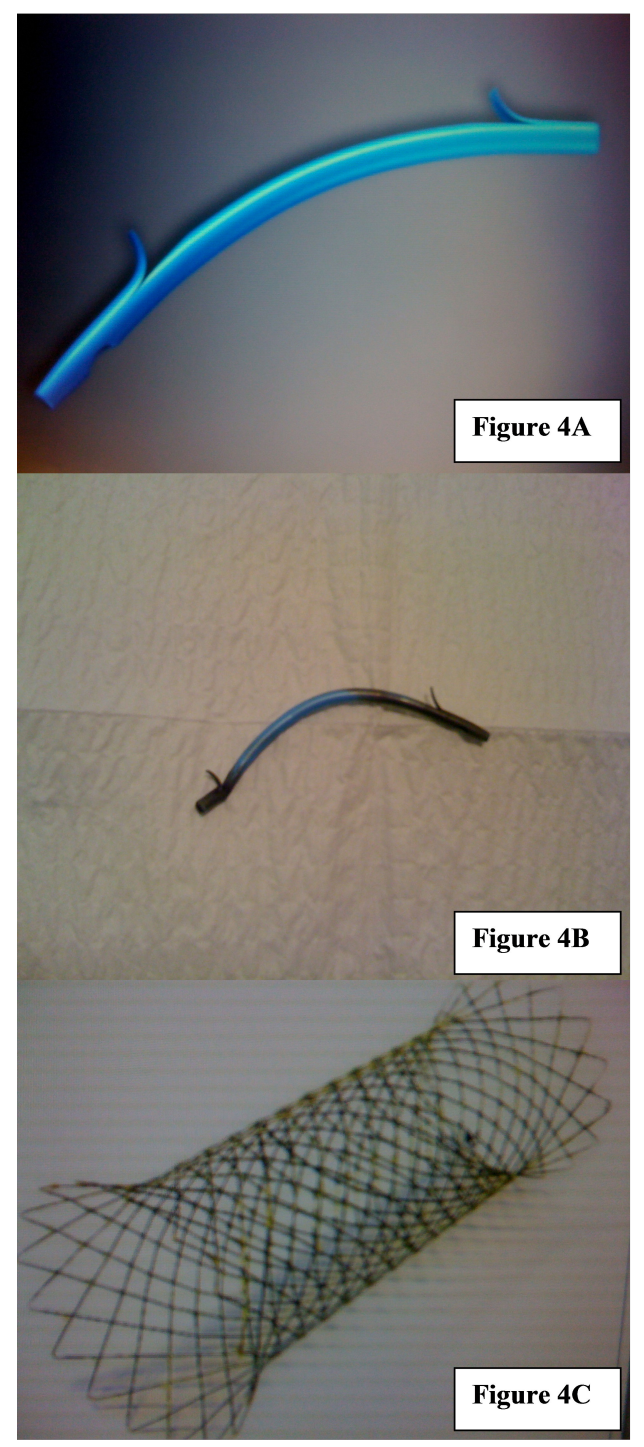

Figure 4. Plastic biliary stent inserted in a patient with anastomotic biliary leak after cadaveric liver transplantation. The patient developed leukocytosis associated with new onset of jaundice and abdominal pain. A CT scan revealed a large sub-hepatic fluid collection that was percutaneosly drained. The fluid aspirated was consistent with bile. During the following days, the 24 hours drain output was consistently above $400 \mathrm{ml}$. An ERCP confirmed the presence of a bile duct anastomotic partial dehiscence. A 10 French, $9 \mathrm{~cm}$ in length temporary plastic stent (Figure 4A) was inserted across the anastomosis. During the following days, the drainage output decreased and on post-ERCP day 7 the patient had no bile draining from the percutaneous drainage tha was subsequently taken out. After 3 months, the plastic stent was removed during a second ERCP (Figure 4B) and the endoscopic cholangiogram revealed a complete resolu- 
tion of the leak and no anastomotic stricture. Figure 4C represents a non-covered metallic biliary stent with diameter of $10 \mathrm{~mm}$ and $6 \mathrm{~cm}$ length. These stents are usually used for malignant biliary obstructions but, when covered by a non-adsorbable layer that prevent tissue ingrowth into the stent, can be removed and are becoming popular even for the treatment of benign biliary strictures and for post liver transplant biliary leaks. The advantages of metallic stents, in comparison to plastic stents, are: larger diameters that result in longer patency rates, self-expanding material that allows constant dilatation in the areas of biliary stenosis, more flexibility and therefore better adherence to the biliary walls. This last characteristic is very important when dealing with biliary leaks as covered metallic stents are able to prevent bile extravasation and facilitate non-operative management even in severe anastomotic bile disruptions.

Metal stents can also be differentiated on the basis of stent composition, with namely stainless steel or nitinol being used. Nitinol is an example of a biocompatible, super-elastic, and shape memory alloy consisting of 55\% nickel and $45 \%$ titanium. The strong inter-metallic bonds between nickel and titanium have a very low reaction rate; thus, preventing immunological responses and a decreased rate of corrosion.

Initially, SEMS featured an uncovered design but a limited patency on the account of tissue overgrowth, cancer ingrowth [77] and poor removability led to the development of covered self-expanding metal stents (CSEMS). These stents have a metallic skeleton and are covered by a biocompatible, synthetic covering, which is resistant to the effects of bile, gastric, and pancreatic secretions [78]. The increased incidence of migration associated with CSEMS, however, paved the way for the development of partially CSEMS in which the distal and proximal ends of the stent are uncovered and therefore prevent the risk of stent migration.

\section{Postoperative biliary complications}

\subsection{Leaks}

Bile leaks after LT occur in 2-25\% of patients [79] and most present within one to three months after surgery. Anastomotic dehiscences are due to technical errors, tension or for ischemia of the bile duct edges due to hepatic artery thrombosis or because of devascularization of the tissue surrounding the biliary tree. In addition, bile leaks can also occur from the cystic duct remnants, the T-tube site or tract, from the gallbladder fossa or (in the case of living donor LT) from the cut surface of the liver (Table 8).

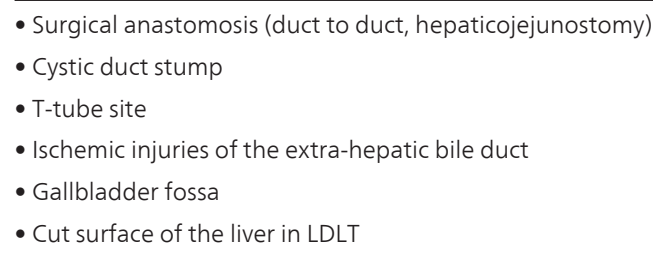

Table 8. Causes and locations of leaks following liver transplantation.

Early leaks (within 4 weeks from LT) are usually due to ischemia or technical issues [80]. Late bile leaks tend to occur following T-tube removal [80], as patients on high dose of steroids and 
other immunosuppressive medications have reduced ability to heal the T-tube insertion site and seal the tract around the drain. Post LT bile leaks should be suspected in patients who develop clinical deterioration, signs of peritoneal inflammation or fluid collections on cross sectional imaging tests. A bile leak should also be suspected in patients who develop persistent abdominal pain after removal of T-tube. It is very important to be aware that a relatively high proportion of patients with late bile leaks present with late biliary strictures than do those with early leaks.

Many bile leaks can be resolved non-operatively with early percutaneous or endoscopic interventions [50-52,55]. When there is a low suspicion of a biliary leak, a radionucleotide scan has reasonable accuracy for the presence of bile extravasation [81]. ERCP, though, is the gold standard diagnostic method and should be performed in all patients when there is a high suspicion for biliary leaks. Treatment for biliary leaks consists of placement of either an endoscopic stent and/or a percutaneous stent/drain. If there is an associated stricture, then both the leak and the stricture need to be bridged by the stent. Stent placement can result in up to $88 \%$ resolution of biliary leaks. Resolution of the leak occurs typically within 5 weeks but the patient's symptoms will resolve within days of stent insertion [82]. The stent should be left in place for approximately 2 to 3 months because of problems with delayed healing that may arise as a result of immunosuppression [59]. In cases where a T-tube is in place, small anastomotic leaks can be diagnosed with a T-tube cholangiogram and can be managed by leaving the tube open without further interventions. Instead of the transpapillary stent, a nasobiliary tube can be inserted. An advantage of the nasobiliary tubes is that they permit cholangiographic follow-up without the need for further endoscopies [83], however, they are often poorly tolerated and also divert bile away from the intestine, thereby decreasing the bioavailability of certain drugs.

Anastomotic leaks after Roux-en-Y choledochojejunostomies are less common. A suspected bile leak in such patients can be diagnosed with a hepatobiliaryimino-diacetic acid (HIDA) scan if patients do not have a drainage catheter in place. Standard ERC is often not feasible because of anatomic difficulties in reaching the biliary anastomosis. Management is usually performed with percutaneous internal-external drainage. Bile leaks in patients with Roux-en$\mathrm{Y}$ anatomy more often require surgical management.

Bilomas occur because of bile duct rupture and extravasation of bile into the hepatic parenchyma or the abdominal cavity. Most post-LT bilomas occur in the perihepatic area. Small bilomas communicating with the biliary tree may resolve spontaneously. Large bilomas not communicating with the bile ducts should be treated with percutaneous drainage and antibiotics. Surgery is indicated only when the bile leak cannot be controlled effectively with endoscopic stenting.

\subsection{Bile duct strictures}

\subsubsection{Introduction}

Biliary strictures and bile leaks account for the majority of biliary complications after LT. The incidence of biliary strictures after cadaveric LT ranges between 5 to $15 \%$ while the incidence 
is much higher after living donor liver transplantation where biliary leaks occur in $28-32 \%$ of patients [84]. Although strictures can develop at any time post LT, they tend to occur in the first 5-8 months after surgery $[84,85]$. Strictures that occur early after are mostly attributable to technical problems, whereas late strictures are mainly attributable to vascular insufficiency and problems with the healing of tissues and fibrosis $[63,86]$. A bile leak is an independent risk factor for the development of a stricture, and for that reason, a bile leak requires emergent endoscopic therapy [66]. Strictures are classified as anastomotic (AS) or nonanastomotic (NAS), depending on the stricture site (Table 9). NAS are defined as strictures that occur more than $0.5 \mathrm{~cm}$ proximal to the anastomosis and tend to be multiple and longer in length (Table 9). NAS can be further classified into macroangiopathic, microangiopathic, and immunogenic be the causes determining the stenosis of the bile duct (Table 10) [84, 87].

AS tend to occur later than NAS. They are usually shorter and localized to the anastomotic site (Table 9) with an incidence of 4-9\% [80, 84].Ischemic NAS usually presents within 1 year of OLT while immunological NAS usually present later than 1 year post-transplantation [88, 89]. In contrast to AS, NAS can result in graft loss [90]. AS are generally the result of scar formation (fibrosis), local ischemia, technical issues, or a bile leak in the post-operative period $[89,91]$.

\begin{tabular}{lrr}
\hline & Biliary strictures & \\
\hline Anastomotic & Non-anastomotic & \\
\hline Single & Multiple \\
Short & Long \\
Anastomosis site & Intrahepatitc and proximal to anastomosis \\
\hline
\end{tabular}

Table 9. Classification of biliary strictures.

\begin{tabular}{lll}
\hline Macroangiopathic & Microangiopathic & Immunogenic \\
\hline Hepatic artery thrombosis & Prolonged cold and warm ischemia times & Chronic rejection \\
& Donation after cardiac death & ABO incompatibility \\
& Prolonged use of vasopressors in the donor & Primary sclerosing cholangitis \\
& & Autoimmune hepatitis \\
\hline
\end{tabular}

Table 10. Non-anastomotic stricture classification.

\subsubsection{Anastomotic strictures}

Up to $80 \%$ of biliary strictures are anastomotic, occurring either at the choledocho-choledochostomy or choledocho-jejunostomy sites [51, 55]. AS typically reflect technical problems and primarily are due to small bile leaks resulting in a peri-anastomotic fibroinflammatory response, or ischemia at the end of the bile duct resulting in a fibroproliferative response. By definition, they are single and short in length, making them 
suitable for endoscopic intervention. The characteristic cholangiographic appearance of AS is that of a thin narrowing in the area of the biliary anastomosis. In some patients, a narrowing of the anastomosis may become evident within the first 1 to 2 months after LT because of postoperative edema and inflammation [89]. This type of narrowing has an excellent response to endoscopic balloon dilation and plastic stent placement; in most patients, it resolves within 3 months and the anastomosis remains patent without further intervention. Except for the subset of patients with this early narrowing, most patients with AS require ongoing ERCP sessions (every 2 to 3 months) with balloon dilation and longterm stenting (for 12 to 24 months) (Figure 5). In most cases, an approach using balloon dilation with diameters of 6 to $8 \mathrm{~mm}$ and placement of 7.0- to 11.5-Fr plastic stents is more effective than balloon dilation alone [92]. Stents should be exchanged at 3-month intervals to avoid stent occlusion and the precipitation of bacterial cholangitis. Most patients require several endoscopic interventions (mean of 3 to 5) with long-term success rates in the range of $70 \%$ to $100 \%[52,85,89,92]$. The placement of a progressively increasing number of as well as diameter stents with each subsequent ERC has been shown to be a successful method of treating AS [93]. In an illustrative study, patients who developed biliary strictures after LT and who initially were treated endoscopically with balloon dilation and plastic stents had a recurrence rate of $18 \%$ with a mean time to recurrence of 110 days [94].

There is some clinical experience in temporary placement of a covered self-expanding metal stent to reduce the need for repeated stent exchanges, but data are limited [95]. The difficulty with the uncovered metallic self-expandable stent is that there is an inevitable reactive hyperplasia that can be accompanied by secondary stone formation above the stent and there may be a challenge in removing the stent once it has been in place for 6 to 9 months [96]. Fully covered stents, by contrast, almost always are able to be removed endoscopically, as they do not embed into the surrounding tissue. The data on this type of stent are limited and one article reported the stents caused strictures in the bile duct mainly secondary to the anchoring point in the distal proximal end [97]. Additionally, they may occlude secondary branch ducts, and this technical aspect might limit their use in patients with right-lobe live-donor transplants. Because of the high rates of success, endoscopic management should be considered the first choice before considering percutaneous interventions or surgical repair in patients with ductto-duct anastomosis. In patients with Roux-en-Y choledochojejunostomy, management with balloon enteroscopy ERC or PTC and dilation followed by placement of a percutaneous transhepatic catheter is often necessary. Surgical intervention (usually a repair or conversion to a Roux-en-Y choledochojejunostomy) is required when the ERC or PTC fails to adequately treat AS.

\subsubsection{Non-anastomotic strictures}

NAS result mainly from hepatic artery thrombosis, increased cold ischemia time, or ABO blood-type incompatibility. Less commonly these strictures can be caused by recurrence of the underlying disease such as primary sclerosing cholangitis. They account for $10.0 \%$ to $25.0 \%$ of all stricture complications after LT, with an incidence in the range of $0.5 \%$ to $10.0 \%[51,52,53$, 
$54,55]$. True ischemic strictures occur more than $0.5 \mathrm{~cm}$ proximal to the anastomosis and often involve the hilum and multiple separate obstructions at the level of the sectoral or segmental branch ducts. This can lead to a cholangiographic appearance that resembles primary sclerosing cholangitis. NAS tend to occur earlier than AS, with a mean time to stricture development of 3 to 6 months $[55,59]$.

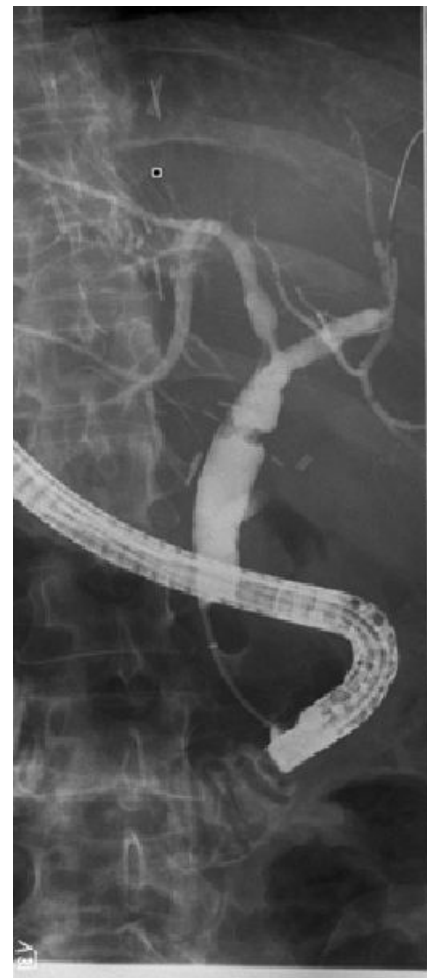

A

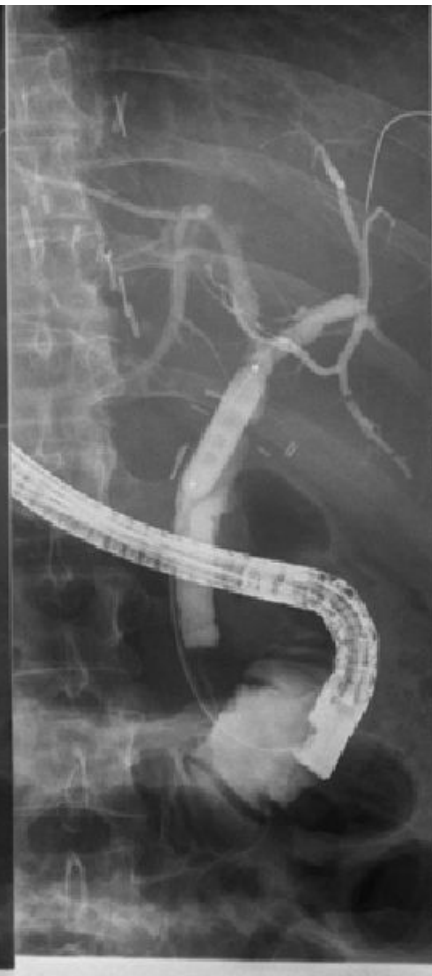

B

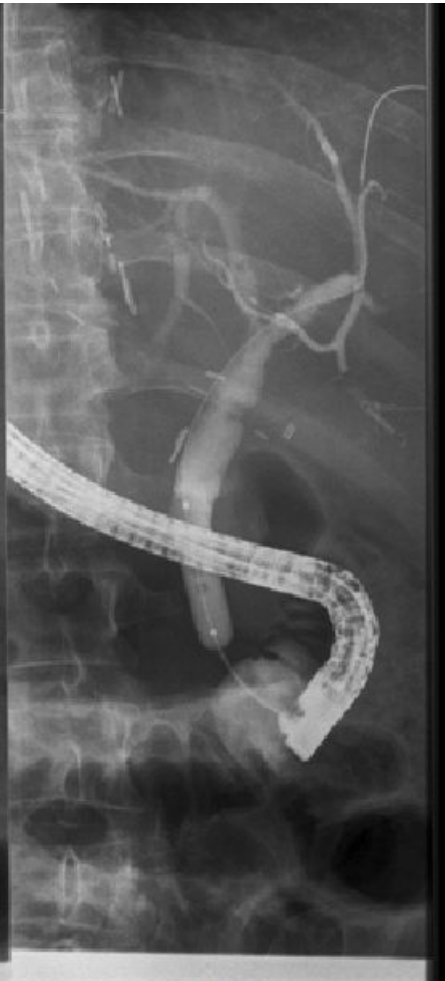

C

Figure 5. Example of anastomotic stricture after cadaveric liver transplantation. A 57 year old man affected by alcoholic cirrhosis underwent a liver transplant nine months before presenting with elevation of the serum total bilirubin and alkaline phosphatase. An abdominal Doppler ultrasound revealed normal portal vein, hepatic veins and hepatic artery flow with mild dilatation of the intra-hepatic bile ducts. An endoscopic retrograde cholangiography (ERCP) was ordered to assess the biliary tree and revealed the presence of a critical anastomotic stricture (Figure 5A, white arrow). An inflatable endoscopic balloon measuring $10 \mathrm{~mm}$ in diameter and $4 \mathrm{~cm}$ in length was used to dilate the anastomotic stricture for 5 minutes (Figure 5B, white triangle). After dilating the anastomotic stricture, an occlusive cholangiogram revealed an almost complete resolution of the anastomotic stenosis (Figure 5C, white arrow).

NAS are generally more difficult to treat than AS and can present with multiple episodes of cholangitis requiring hospitalizations. Endoscopic therapy of NAS typically consists of 4- to 6-mm balloon dilation (compared with 6 to $8 \mathrm{~mm}$ for AS) followed by sphincterotomy, and 
placement of a 10.0- to 11.5-Fr plastic stent with replacement every 3 months [54]. The more aggressive approach with the placement of a progressively increasing number of as well as diameter stents with each subsequent ERC has been shown to be a successful method [93]. However, time to response with NAS is more prolonged than with AS and patients with NAS, in average, require twice the number of interventions as patients with AS. The median time to resolution of the stricture is 4-6 months for NAS versus 2 months for AS [59].

Outcomes of patients with NAS are not as favorable as for patients who develop AS. The 5year graft survival rate is $73 \%$ in patients with NAS, which is significantly lower than in matched controls without strictures [89]. Only $50 \%$ to $75 \%$ of patients have a long-term response with endoscopic therapy with dilation and stent placement [54, 59, 89, 73, 98]. Furthermore, up to $30 \%$ to $50 \%$ of patients will require re-transplantation or will die as a consequence of this complication despite endoscopic therapy [54, 55, 63]. As a general rule, ischemic events that lead to diffuse intrahepatic bile duct strictures are associated with poor graft survival and will require retransplantation for suitable candidates.

Surgical revision may ultimately be required in patients with strictures that are refractory to endoscopic or percutaneous treatment. A Roux-en-Y choledochojejunostomy is usually performed in patients with duct-to-duct anastomosis. In those who already have a Roux-en$\mathrm{Y}$ anastomosis, a revision may be required by repositioning the bile duct of the graft to a more proximal vascularized area.

\subsubsection{Biliary stones, sludge and casts}

Biliary filling defects are identified in approximately $5 \%$ of patients undergoing radiological investigations after LT [99]. The vast majority of filling defects are caused by stones (70\%) followed by sludge, debris, blood clots, casts or migration of biliary stents [54, 89]. Biliary anastomotic stenosis and intrahepatic strictures are the most frequent predisposing conditions since they cause cholestasis and bacterial overgrowth that are well known risk factors for the formation of sludge and biliary stones. Biliary duct stenoses are often caused by preservation injury or by hepatic artery insufficiency. These are the two most common causes of ischemic damage to the biliary tree that is highly dependent on the arterial blood supply for its metabolic needs. When the biliary endothelium does not receive enough arterial blood flow, it sloughs in the lumen of the biliary tree creating an optimal enviroment for the formation of crystals and early calcification of the proteinaceous debris [99].

The management of filling defects in the biliary tree of patients undergoing LT is similar to the non-transplant population and include sphincterotomy or dilatation of the sphincter of Oddi and their extraction with the use of Dormia baskets or biliary balloons with the caveat that in the presence of immunosuppressive agents, patients can have a rapid clinical decline in the presence of undrained infected biliary ducts.

Because of the denervation of the liver graft and the use of steroids and other immunosuppressive medications, LT patients affected by choledocholithiasis can be completely asymptomatic and afebrile even in the presence of bactobilia. LT patients affected by unrecognized biliary occlusion can be completely asymptomatic for a long period of time and present with 
recurrent elevation of cholestatic serum markers that can mimick rejection, fevers of unknown etiology, pancreatitis or cholangitis leading to sepsis and multiorgan failure in a very rapid interval.

\subsubsection{Stones}

Stones usually form in the biliary tree of LT grafts proximally to a stricture or anastomotic stenosis. Cyclosporine is known to promote supersaturation of bile and may contribute to the formation of biliary stones in this group of patients. In one series, biliary stones were diagnosed after a median of 19 months post LT and following their successful extraction, $17 \%$ reoccurred within a median period of only 6 months [73]. In most cases (59\% to 66\%), a single ERCP session with biliary sphincterotomy and balloon or basket extraction was sufficient to clear the bile duct when the stones were located in the extra-hepatic system [73], while 2 or more sessions were needed in $24 \%$ of patients and 3 or more sessions may be required in $17 \%$ of patients [73]. Advanced ERC techniques, such as intraductal lithotripsy or direct choledochoscopy should be considered for all patients with large stones or for those stones located in a more proximal biliary tract [84].

\subsubsection{Casts}

Biliary cast are defined as the presence of hardened, often dark and calcified protenaceous material within the biliary system that takes the physical shape of the bile ducts. Biliary casts are reported in $2.5 \%$ up to $18 \%$ of $\mathrm{LT}$ recipients [84, 99, 100]. Acute cellular rejection, ischemia, infection, and biliary obstruction are well known risk factors for the development of casts after LT.Most commonly they develop in the setting of ischemia, for example after the development of hepatic artery thrombosis and when there is stricturing of the biliary tree at the hilum [64]. The formation of biliary casts is associated with increased morbidity, mortality, and incidence of rejection [84]. Typically it occurs within the first year after transplantation. Analysis of the casts has shown that bilirubin is the primary element along with collagen, bile acid, and cholesterol [101, 102, 103]. The true pathogenesis of biliary cast syndrome is unknown but it is believed that ischemic factors and biliary strictures play an important role in its development. Another risk factor is an increase in warm ischemia time [103]. Several endoscopic approaches have been described with variable success and often multiple procedures are required. Unfortunately it has been reported that up to $22 \%$ of patients with biliary cast syndrome will require retransplantation. Complete clearance of casts can be done in $60 \%$ of patients by ERCP or when necessary by PTC [64]. Various combinations of sphincterotomy, balloon and basket extraction, stent placement, and lithotripsy are often necessary in all those situations where casts are difficult to extract or are located in multiple branches of the biliary tree. Surgery is necessary only when endoscopic or percutaneous methods fail.

\subsubsection{Sphincter of Oddi dysfunction}

The sphincter of Oddi is a muscular structure that encompasses the confluence of the distal common bile and the pancreatic duct as they penetrate the wall of the duodenum. The term sphincter of Oddi dysfunction (SOD) has been used to describe a clinical syndrome of biliary 
or pancreatic obstruction related to mechanical or functional abnormalities of the sphincter of Oddi. The true incidence of SOD after LT is not known but appears to a relatively rare condition. It is postulated that in the posttransplant setting, denervation of the common bile duct in the ampullary region secondary to surgical intervention may lead to the development of a hypertonic sphincter causing SOD. The prevalence of SOD has been reported to be between $2 \%$ to $7 \%[50,98]$ and should be suspected in patients with cholestasis and with a uniformly dilated bile duct without filling defects. In LT recipients affected by SOD, abdominal pain may not be present and can cause post-operative pancreatitis. SOD should be ruled out when other causes of pancreatitis have not been found. The treatment of post LT patients affected by SOD is endoscopic sphincterotomy that allows the release of the muscles of the sphincter with reduction of the intra-luminal biliary and pancreatic hypertension. As for SOD in the nontransplant setting, the risk of pancreatitis after an ERC is high and so temporary prophylactic pancreatic stents after sphincterotomy should be placed if possible to avoid this risk.

\section{Biliary complications after living donation and cardiac arrest}

Biliary complications after LT from living donors and grafts from donors after cardiac death are more frequent than in patients who receive full size grafts from brain dead donors. These two groups of recipients represent an increasing number of patients as the available grafts from brain dead donors have failed to match the needs of patients waiting for LT and need some considerations.

Living donor grafts are obtained by removing the right or left hepatic lobes from healthy donors. The advantages of using living donor grafts are the fact that the quality of the grafts is usually excellent, that surgery can be performed electively when the recipient is in optimal medical conditions and that the cold and warm ischemia times are minimized. On the other hand, living donor LT is technically challenging as the liver graft is only a portion of the entire liver and therefore there is an increased risk of perioperative hepatic insufficiency. The increased risk of hepatic artery thrombosis is due to the fact that the lumen of the proper hepatic artery is significantly smaller than the common hepatic artery and more prone to develop intraluminal clots. In addition, there is an increased risk for bile leaking out from the interrupted intrahepatic ducts during the dissection of the liver parenchyma and, biliary leaks at the level of the anastomoses between the right or left biliary ducts and the recipient's native common bile duct or the Roux-en-Y loop. These anastomoses are often characterized by their small caliber and the fact that, often, there are several ducts that need to be put together.

The use of donors after cardiac arrest in LT has become an acceptable strategy to increase the number of available grafts. The early experience with these grafts was considered acceptable and several programs have embraced this practice. However, recent studies have reported that the short and long term outcomes are inferior to grafts from donors who suffered brain death. Among the most common causes of perioperative complications in this group are: biliary necrosis, anastomotic and non-anastomotic strictures, anastomotic leaks and non-primary graft function. These adverse events seem to be consequences of the warm ischemic insult 
occurring in hemodinamically unstable patients prior and during the obervation period leading to cardiac arrest.

\subsection{Recipients of living-donor liver grafts}

Living-donor liver transplantation (LDLT) has been associated with a higher rate of bile leaks than in comparision to deceased-donor LT: $31.8 \%$ versus $10.2 \%$, respectively [104]. Factors associated with increased biliary leaks are:the presence of 3 or more bile ducts, presence of hepatitis $\mathrm{C}$, the experience of the transplant center at performing LDLT,long duration of surgery, donor age older than 50, and recipients with MELD greater than 35 [105, 45]. The most likely reason for these complications include a relatively smaller duct size, hence a more technically difficult anastomosis, and a higher chance of ischemic injury to the allograft [106]. Overall, biliary complications occur more frequently in recipients receiving a right graft than a left liver graft. In right liver graft recipients with single biliary reconstruction, duct-to-duct anastomosis involving a small-sized duct $(<4 \mathrm{~mm}$ in diameter $)$ is more of a risk for biliary complications than when a hepatico-jejunostomy is used with these duct sizes [107]. A decreased incidence of biliary complications with a Roux-en-Y reconstruction has been found in some [104], but not all, studies [108]. Endoscopic management in LDLT recipients may be quite difficult because of the complex nature of the duct-to-duct reconstruction. Patients will often require frequent endoscopic retrograde cholangiographies (ERCs) with the use of smaller caliber stents (7.0-8.5 Fr). ERC with balloon dilatation is successful in up to $65 \%$ of patients. Failure of a primary ERC with dilatation is associated with the appearance of late biliary strictures over 24 weeks from LT and more than 8 weeks between a twofold increase in serum alkaline phosphatase [109]. The relapse rate of strictures is up to $30 \%$ and occurs more in patients with shorter duration of stenting. In addition to the recipient, donors also experience biliary complications and should be made aware of this before undergoing donation. In a multicenter study that evaluated the outcome of 393 donors, bile leaks occurred in 36 patients $(9 \%)$ and most of these patients required a prolonged intensive care unit stay [110]. Biliary complications in donors are seen more often with right lobe donation and the management is the same as described for the recipients.

\subsection{Recipients of grafts from donation after cardiac death}

The continuing shortage of organs has led to expansion of the donor pool and consideration of non-heart beating liver donation or donation after cardiac death (DCD). DCD is associated with significant risk for both early and late biliary complications. In a retrospective analysis of 20 recipients of organs from DCD in the United States, 12 out of 20 patients $(60 \%)$ developed serious biliary complications [65]. Most recipients developed more than one biliary complication including bile leaks requiring liver re-transplantation, anastomotic strictures, hilar strictures, extra-hepatic donor duct stricture, stones, casts, and biliary debris. In $50 \%$ of the patients, biliary strictures were proximal to the anastomosis. Unlike conventional liver transplantation where non-anastomotic strictures (NAS)are usually attributed to ischemic preservation injury or vascular compromise due to hepatic artery failure, NAS in DCD recipients reflects ischemic injury that occurred before organ retrieval [65]. An analysis of 172 
Korean recipient survivors confirmed the increased rate of biliary complications in DCDrelated liver transplantation [111] and also illustrated the impact of the location of the stricture and its relation to graft survival. Patients with unilateral or at the confluence biliary strictures could be managed endoscopically with dilatation and stenting while diffuse or bilateral strictures failed endoscopic interventions [111, 112, 113]. Unilateral and bilateral or diffuse biliary strictures were associated with 86 and $0 \%$ long-term survival, respectively [111, 112, 113]. Intra-hepatic biliary strictures are also associated with increased incidence of biliary sludge, cast formation, recurrent cholangitis, and biliary fibrosis [65].

\section{Future directions}

Use of new intraductal endoscopy technologies such as the SpyGlass ${ }^{\circledR}$ direct visualization system (Boston Scientific ${ }^{\circledR}$, Natick, MA, USA), which allows visualization of the inner wall of the biliary tree and can act as the guidance system for passage of the guide wire through a tight stricture, has shown some early promise in this area $[84,114,115,116]$. New types of balloons and stents will have significant role in improvement of management of biliary stricture. Preliminary evidence shows that peripheral cutting balloons may be more effective for the treatment of benign biliary strictures not responsive to standard balloon dilatation [117]. Metal stents have been employed in an effort to reduce stricture recurrence and maintain duct patency. Traditional open-mesh metal stents are associated with occlusion, stone formation and epithelial hyperplasia that reduce their patency rate [118]. These disadvantages of metal stents have traditionally limited their use for benign biliary strictures. The drawbacks of uncovered metal stents have led to the development of covered metal stents, as they can be removed during ERCP after the resolution of the biliary complication. However, the use of covered metal stents for the management of biliary complications in LT recipients needs further evaluation, as their safety and effectiveness have not been fully established. New technologies have introduced the possibility of employing self-expanding stents made of bioabsorbable material that theoretically will offer several advantages compared to the plastic and self-expanding metal stents [119, 120]. Studies in porcine models have shown that these stents have better patency rates because of their larger diameter, lower biofilm accumulation and reduced incidence of bile duct proliferative changes that often cause occlusion of metallic stents. Furthermore, patients do not have to undergo additional procedures to remove the stents. Bioabsorbable stents can also be impregnated with pharmaceutical compounds, such as antimicrobial agents that make them an optimal choice for patients who are affected by local biliary infections. However, these stents remains investigational at the present time.

\section{Summary}

The overall landscape of the management of biliary complications after LT has changed rather rapidly in the past 2 decades. In the past, the conventional management of these conditions was mainly surgical. With the advancement of endoscopic equipments and accessories, therapeutic endoscopy has been playing a major role in the treatment of post-liver transplant biliary complications. Percutaneous and surgical modalities are now reserved only for patients 
in whom endoscopic treatment fails and for those with multiple inaccessible intrahepatic strictures or Roux-en-Y anastomoses.

\section{Abbreviations}

Liver Transplant (LT)

Acute Liver Failure (ALF)

End Stage Liver Disease (ESLD)

United States(US)

Hepatocellular Carcinoma (HCC)

University of California, San Francisco (UCSF)

Cholangiocarcinoma (CC)

United Network for Organ Sharing (UNOS)

Model for End-stage Liver Disease (MELD)

Pediatric End-stage Liver Disease (PELD)

International Normalized Ratio (INR)

Endoscopic Retrograde Cholangio-Pancreatography (ERCP)

PercutaneousTranshepatic Cholangiography (PTC)

Percutaneous Transhepatic Biliary Drainage (PTBD)

Self-Expandable Metallic Stents (SEMS)

HepatobiliaryImino-DiaceticAcid Scan (HIDA) Scan

Anastomotic Strictre(AS)

Non-anastomotic Stricture (NAS)

Sphincter of Oddi Dysfunction (SOD)

\section{Author details}

Bassam Abu-Wasel, Paul D. Renfrew and Michele Molinari*

*Address all correspondence to: michele.molinari@cdha.nshealth.ca

Department of Surgery and Transplantation, Dalhousie University, Halifax, Nova Scotia, Canada 


\section{References}

[1] Starzl TE, Marchioro TL, Vonkaulla KN, Hermann G, Brittain RS, Waddell WR. Homotransplantation of the Liver in Humans. Surg Gynecol Obstet 1963;117:659-76.

[2] Yu AS, Keeffe EB, editors. “Liver transplantation,” in Hepatology, 2003.

[3] Murray KCR. AASLD practice guidelines: evaluation of the patient for liver transplantation. Hepatology 2005;41(6):1407-32.

[4] Conference C. Consensus conference: indications for Liver Transplantation, LyonPalais Des Congr'es: text of recommendations (long version). Liver Transplantation, 2006:988-1011.

[5] Ahmed A, Keeffe EB. Current indications and contraindications for liver transplantation. Clin Liver Dis 2007;11(2):227-47.

[6] Jain A, Reyes J, Kashyap R, Dodson SF, Demetris AJ, Ruppert K, et al. Long-term survival after liver transplantation in 4,000 consecutive patients at a single center. Ann Surg 2000;232(4):490-500.

[7] Gordon RD, Fung J, Tzakis AG, Todo S, Stieber A, Bronsther O, et al. Liver transplantation at the University of Pittsburgh, 1984 to 1990. Clin Transpl 1991:105-17.

[8] Abbasoglu O, Levy MF, Brkic BB, Testa G, Jeyarajah DR, Goldstein RM, et al. Ten years of liver transplantation: an evolving understanding of late graft loss. Transplantation 1997;64(12):1801-7.

[9] Asfar S, Metrakos P, Fryer J, Verran D, Ghent C, Grant D, et al. An analysis of late deaths after liver transplantation. Transplantation 1996;61(9):1377-81.

[10] Kim WR. The burden of hepatitis C in the United States. Hepatology 2002;36(5 Suppl 1):S30-4.

[11] Brown RS, Jr., Lake JR. The survival impact of liver transplantation in the MELD era, and the future for organ allocation and distribution. Am J Transplant 2005;5(2):203-4.

[12] U.S. Department of Health and Human Services HRaSA, Healthcare Systems Bureau, Division of Transplantation, Rockville, MD., editor. Annual Report of the U.S. Organ Procurement and Transplantation Network and the Scientific Registry of Transplant Recipients: Transplant Data 1999-2008, 2009.

[13] Seaberg EC, Belle SH, Beringer KC, Schivins JL, Detre KM. Liver transplantation in the United States from 1987-1998: updated results from the Pitt-UNOS Liver Transplant Registry. Clin Transpl 1998:17-37.

[14] Ritt DJ, Whelan G, Werner DJ, Eigenbrodt EH, Schenker S, Combes B. Acute hepatic necrosis with stupor or coma. An analysis of thirty-one patients. Medicine (Baltimore) 1969;48(2):151-72. 
[15] Larson AM. Diagnosis and management of acute liver failure. Curr Opin Gastroenterol 2010;26(3):214-21.

[16] Larson AM, Polson J, Fontana RJ, Davern TJ, Lalani E, Hynan LS, et al. Acetaminophen-induced acute liver failure: results of a United States multicenter, prospective study. Hepatology 2005;42(6):1364-72.

[17] Rosen CB, Heimbach JK, Gores GJ. Liver transplantation for cholangiocarcinoma. Transpl Int 2010;23(7):692-7.

[18] Mazzaferro V, Regalia E, Doci R, Andreola S, Pulvirenti A, Bozzetti F, et al. Liver transplantation for the treatment of small hepatocellular carcinomas in patients with cirrhosis. N Engl J Med 1996;334(11):693-9.

[19] Yao FY, Ferrell L, Bass NM, Watson JJ, Bacchetti P, Venook A, et al. Liver transplantation for hepatocellular carcinoma: expansion of the tumor size limits does not adversely impact survival. Hepatology 2001;33(6):1394-403.

[20] Gores GJ, Heimbach JK, Rosen CB. Liver transplantation for nonhepatocellular carcinoma malignancies. Liver Transplantation 2010;16:S22-25.

[21] Facciuto ME, Singh MK, Katta U, Samaniego S, Sharma J, Rodriguez-Davalos M, et al. Liver transplantation for hepatocellular carcinoma: defining the impact of using extended criteria liver allografts. Transplantation 2011;92(4):446-52.

[22] Rodrigue JR, Hanto DW, Curry MP. Patients' willingness to accept expanded criteria donor liver transplantation. Am J Transplant 2011;11(8):1705-11.

[23] Ali JM, Bonomo L, Brais R, Griffiths WJ, Lomas DJ, Huguet EL, et al. Outcomes and diagnostic challenges posed by incidental cholangiocarcinoma after liver transplantation. Transplantation 2011;91(12):1392-7.

[24] Mathurin P, Moreno C, Samuel D, Dumortier J, Salleron J, Durand F, et al. Early liver transplantation for severe alcoholic hepatitis. N Engl J Med 2011;365(19):1790-800.

[25] Kelly DA. Current issues in pediatric transplantation. Pediatr Transplant 2006;10(6): 712-20.

[26] Berg CL, Steffick DE, Edwards EB, Heimbach JK, Magee JC, Washburn WK, et al. Liver and intestine transplantation in the United States 1998-2007. Am J Transplant 2009;9(4 Pt 2):907-31.

[27] Magee JC, Krishnan SM, Benfield MR, Hsu DT, Shneider BL. Pediatric transplantation in the United States, 1997-2006. Am J Transplant 2008;8(4 Pt 2):935-45.

[28] Martin SR, Atkison P, Anand R, Lindblad AS. Studies of Pediatric Liver Transplantation 2002: patient and graft survival and rejection in pediatric recipients of a first liver transplant in the United States and Canada. Pediatr Transplant 2004;8(3):273-83. 
[29] Freeman RB, Jr., Wiesner RH, Roberts JP, McDiarmid S, Dykstra DM, Merion RM. Improving liver allocation: MELD and PELD. Am J Transplant 2004;4 Suppl 9:114-31.

[30] Verran DJ, Asfar SK, Ghent CN, Grant DR, Wall WJ. Biliary reconstruction without T tubes or stents in liver transplantation: report of 502 consecutive cases. Liver Transpl Surg 1997;3(4):365-73.

[31] Neuhaus P, Blumhardt G, Bechstein WO, Steffen R, Platz KP, Keck H. Technique and results of biliary reconstruction using side-to-side choledochocholedochostomy in 300 orthotopic liver transplants. Ann Surg 1994;219(4):426-34.

[32] Ringe B, Oldhafer K, Bunzendahl H, Bechstein WO, Kotzerke J, Pichlmayr R. Analysis of biliary complications following orthotopic liver transplantation. Transplant Proc 1989;21(1 Pt 2):2472-6.

[33] Calne RY. A new technique for biliary drainage in orthotopic liver transplantation utilizing the gall bladder as a pedicle graft conduit between the donor and recipient common bile ducts. Ann Surg 1976;184(5):605-9.

[34] Anselmi M, Sherlock D, Buist L, Zundel N, Badger I, McMaster P, et al. Gallbladder conduit vs end-to-end anastomosis of the common bile duct in orthotopic liver transplantation. Transplant Proc 1990;22(5):2295-6.

[35] Halff G, Todo S, Hall R, Starzl TE. Late complications with gallbladder conduit biliary reconstruction after liver transplantation. Transplantation 1989;48(3):537-9.

[36] Hiatt JR, Quinones-Baldrich WJ, Ramming KP, Brems J, Busuttil RW. Operations upon the biliary tract during transplantation of the liver. Surg Gynecol Obstet 1987;165(1):89-93.

[37] Vallera RA, Cotton PB, Clavien PA. Biliary reconstruction for liver transplantation and management of biliary complications: overview and survey of current practices in the United States. Liver Transpl Surg 1995;1(3):143-52.

[38] Northover JM, Terblanche J. A new look at the arterial supply of the bile duct in man and its surgical implications. Br J Surg 1979;66(6):379-84.

[39] Stapleton GN, Hickman R, Terblanche J. Blood supply of the right and left hepatic ducts. Br J Surg 1998;85(2):202-7.

[40] Azoulay D, Marin-Hargreaves G, Castaing D, ReneAdam, Bismuth H. Duct-to-duct biliary anastomosis in living related liver transplantation: the Paul Brousse technique. Arch Surg 2001;136(10):1197-200.

[41] Shokouh-Amiri MH, Grewal HP, Vera SR, Stratta RJ, Bagous W, Gaber AO. Duct-toduct biliary reconstruction in right lobe adult living donor liver transplantation. J Am Coll Surg 2001;192(6):798-803. 
[42] Rogiers X, Malago M, Gawad K, Jauch KW, Olausson M, Knoefel WT, et al. In situ splitting of cadaveric livers. The ultimate expansion of a limited donor pool. Ann Surg 1996;224(3):331-9; discussion 39-41.

[43] Azoulay D, Astarcioglu I, Bismuth H, Castaing D, Majno P, Adam R, et al. Split-liver transplantation. The Paul Brousse policy. Ann Surg 1996;224(6):737-46; discussion $46-8$.

[44] Ishiko T, Egawa H, Kasahara M, Nakamura T, Oike F, Kaihara S, et al. Duct-to-duct biliary reconstruction in living donor liver transplantation utilizing right lobe graft. Ann Surg 2002;236(2):235-40.

[45] Liu CL, Lo CM, Chan SC, Fan ST. Safety of duct-to-duct biliary reconstruction in right-lobe live-donor liver transplantation without biliary drainage. Transplantation 2004;77(5):726-32.

[46] Deshpande RR, Bowles MJ, Vilca-Melendez H, Srinivasan P, Girlanda R, Dhawan A, et al. Results of split liver transplantation in children. Ann Surg 2002;236(2):248-53.

[47] Miller CM, Gondolesi GE, Florman S, Matsumoto C, Munoz L, Yoshizumi T, et al. One hundred nine living donor liver transplants in adults and children: a single-center experience. Ann Surg 2001;234(3):301-11; discussion 11-2.

[48] Soejima Y, Shimada M, Suehiro T, Kishikawa K, Minagawa R, Hiroshige S, et al. Feasibility of duct-to-duct biliary reconstruction in left-lobe adult-living-donor liver transplantation. Transplantation 2003;75(4):557-9.

[49] Kawachi S, Shimazu M, Wakabayashi G, Hoshino K, Tanabe M, Yoshida M, et al. Biliary complications in adult living donor liver transplantation with duct-to-duct hepaticocholedochostomy or Roux-en-Y hepaticojejunostomy biliary reconstruction. Surgery 2002;132(1):48-56.

[50] Stratta RJ, Wood RP, Langnas AN, Hollins RR, Bruder KJ, Donovan JP, et al. Diagnosis and treatment of biliary tract complications after orthotopic liver transplantation. Surgery 1989;106(4):675-83; discussion 83-4.

[51] Greif F, Bronsther OL, Van Thiel DH, Casavilla A, Iwatsuki S, Tzakis A, et al. The incidence, timing, and management of biliary tract complications after orthotopic liver transplantation. Ann Surg 1994;219(1):40-5.

[52] Rerknimitr R, Sherman S, Fogel EL, Kalayci C, Lumeng L, Chalasani N, et al. Biliary tract complications after orthotopic liver transplantation with choledochocholedochostomy anastomosis: endoscopic findings and results of therapy. Gastrointest Endosc 2002;55(2):224-31.

[53] Pfau PR, Kochman ML, Lewis JD, Long WB, Lucey MR, Olthoff K, et al. Endoscopic management of postoperative biliary complications in orthotopic liver transplantation. Gastrointest Endosc 2000;52(1):55-63. 
[54] Thuluvath PJ, Atassi T, Lee J. An endoscopic approach to biliary complications following orthotopic liver transplantation. Liver Int 2003;23(3):156-62.

[55] Thethy S, Thomson B, Pleass H, Wigmore SJ, Madhavan K, Akyol M, et al. Management of biliary tract complications after orthotopic liver transplantation. Clin Transplant 2004;18(6):647-53.

[56] Brown RS, Jr., Russo MW, Lai M, Shiffman ML, Richardson MC, Everhart JE, et al. A survey of liver transplantation from living adult donors in the United States. N Engl J Med 2003;348(9):818-25.

[57] Reichert PR, Renz JF, Rosenthal P, Bacchetti P, Lim RC, Roberts JP, et al. Biliary complications of reduced-organ liver transplantation. Liver Transpl Surg 1998;4(5):343-9.

[58] Colonna JO, 2nd, Shaked A, Gomes AS, Colquhoun SD, Jurim O, McDiarmid SV, et al. Biliary strictures complicating liver transplantation. Incidence, pathogenesis, management, and outcome. Ann Surg 1992;216(3):344-50; discussion 50-2.

[59] Thuluvath PJ, Pfau PR, Kimmey MB, Ginsberg GG. Biliary complications after liver transplantation: the role of endoscopy. Endoscopy 2005;37(9):857-63.

[60] Scatton O, Meunier B, Cherqui D, Boillot O, Sauvanet A, Boudjema K, et al. Randomized trial of choledochocholedochostomy with or without a $\mathrm{T}$ tube in orthotopic liver transplantation. Ann Surg 2001;233(3):432-7.

[61] Vougas V, Rela M, Gane E, Muiesan P, Melendez HV, Williams R, et al. A prospective randomised trial of bile duct reconstruction at liver transplantation: $\mathrm{T}$ tube or no T tube? Transpl Int 1996;9(4):392-5.

[62] Sotiropoulos GC, Sgourakis G, Radtke A, Molmenti EP, Goumas K, Mylona S, et al. Orthotopic liver transplantation: T-tube or not T-tube? Systematic review and metaanalysis of results. Transplantation 2009;87(11):1672-80.

[63] Pascher A, Neuhaus P. Biliary complications after deceased-donor orthotopic liver transplantation. J Hepatobiliary Pancreat Surg 2006;13(6):487-96.

[64] Davidson BR, Rai R, Kurzawinski TR, Selves L, Farouk M, Dooley JS, et al. Prospective randomized trial of end-to-end versus side-to-side biliary reconstruction after orthotopic liver transplantation. Br J Surg 1999;86(4):447-52.

[65] Maheshwari A, Maley W, Li Z, Thuluvath PJ. Biliary complications and outcomes of liver transplantation from donors after cardiac death. Liver Transpl 2007;13(12): 1645-53.

[66] Welling TH, Heidt DG, Englesbe MJ, Magee JC, Sung RS, Campbell DA, et al. Biliary complications following liver transplantation in the model for end-stage liver disease era: effect of donor, recipient, and technical factors. Liver Transpl 2008;14(1):73-80. 
[67] Rizk RS, McVicar JP, Emond MJ, Rohrmann CA, Jr., Kowdley KV, Perkins J, et al. Endoscopic management of biliary strictures in liver transplant recipients: effect on patient and graft survival. Gastrointest Endosc 1998;47(2):128-35.

[68] Schwartz DA, Petersen BT, Poterucha JJ, Gostout CJ. Endoscopic therapy of anastomotic bile duct strictures occurring after liver transplantation. Gastrointest Endosc 2000;51(2):169-74.

[69] Mosca S, Militerno G, Guardascione MA, Amitrano L, Picciotto FP, Cuomo O. Late biliary tract complications after orthotopic liver transplantation: diagnostic and therapeutic role of endoscopic retrograde cholangiopancreatography. J Gastroenterol Hepatol 2000;15(6):654-60.

[70] Mata A, Bordas JM, Llach J, Gines A, Mondelo F, Lopez Serrano A, et al. ERCP in orthotopic liver transplanted patients. Hepatogastroenterology 2004;51(60):1801-4.

[71] Solmi L, Cariani G, Leo P, Miracolo A, Nigro G, Roda E. Results of endoscopic retrograde cholangiopancreatography in the treatment of biliary tract complications after orthotopic liver transplantation: our experience. Hepatogastroenterology 2007;54(76): 1004-8.

[72] Shastri YM, Hoepffner NM, Akoglu B, Zapletal C, Bechstein WO, Caspary WF, et al. Liver biochemistry profile, significance and endoscopic management of biliary tract complications post orthotopic liver transplantation. World J Gastroenterol 2007;13(20):2819-25.

[73] Park JS, Kim MH, Lee SK, Seo DW, Lee SS, Han J, et al. Efficacy of endoscopic and percutaneous treatments for biliary complications after cadaveric and living donor liver transplantation. Gastrointest Endosc 2003;57(1):78-85.

[74] Kim ES, Lee BJ, Won JY, Choi JY, Lee DK. Percutaneous transhepatic biliary drainage may serve as a successful rescue procedure in failed cases of endoscopic therapy for a post-living donor liver transplantation biliary stricture. Gastrointest Endosc 2009;69(1):38-46.

[75] Soehendra N, Reynders-Frederix V. [Palliative biliary duct drainage. A new method for endoscopic introduction of a new drain]. Dtsch Med Wochenschr 1979;104(6): 206-7.

[76] LaBerge JM, Doherty M, Gordon RL, Ring EJ. Hilar malignancy: treatment with an expandable metallic transhepatic biliary stent. Radiology 1990;177(3):793-7.

[77] Cantu P, Hookey LC, Morales A, Le Moine O, Deviere J. The treatment of patients with symptomatic common bile duct stenosis secondary to chronic pancreatitis using partially covered metal stents: a pilot study. Endoscopy 2005;37(8):735-9.

[78] Bezzi M, Zolovkins A, Cantisani V, Salvatori FM, Rossi M, Fanelli F, et al. New ePTFE/FEP-covered stent in the palliative treatment of malignant biliary obstruction. J Vasc Interv Radiol 2002;13(6):581-9. 
[79] Londono MC, Balderramo D, Cardenas A. Management of biliary complications after orthotopic liver transplantation: the role of endoscopy. World J Gastroenterol 2008;14(4):493-7.

[80] Scanga AE, Kowdley KV. Management of biliary complications following orthotopic liver transplantation. Curr Gastroenterol Rep 2007;9(1):31-8.

[81] Roca I, Ciofetta G. Hepatobiliary scintigraphy in current pediatric practice. Q J Nucl Med 1998;42(2):113-8.

[82] Morelli J, Mulcahy HE, Willner IR, Cunningham JT, Draganov P. Long-term outcomes for patients with post-liver transplant anastomotic biliary strictures treated by endoscopic stent placement. Gastrointest Endosc 2003;58(3):374-9.

[83] Saab S, Martin P, Soliman GY, Machicado GA, Roth BE, Kunder G, et al. Endoscopic management of biliary leaks after T-tube removal in liver transplant recipients: nasobiliary drainage versus biliary stenting. Liver Transpl 2000;6(5):627-32.

[84] 84. Sharma S, Gurakar A, Jabbour N. Biliary strictures following liver transplantation: past, present and preventive strategies. Liver Transpl 2008;14(6):759-69.

[85] Pasha SF, Harrison ME, Das A, Nguyen CC, Vargas HE, Balan V, et al. Endoscopic treatment of anastomotic biliary strictures after deceased donor liver transplantation: outcomes after maximal stent therapy. Gastrointest Endosc 2007;66(1):44-51.

[86] Testa G, Malago M, Broelseh CE. Complications of biliary tract in liver transplantation. World J Surg 2001;25(10):1296-9.

[87] Moench C, Moench K, Lohse AW, Thies J, Otto G. Prevention of ischemic-type biliary lesions by arterial back-table pressure perfusion. Liver Transpl 2003;9(3):285-9.

[88] Buis CI, Verdonk RC, Van der Jagt EJ, van der Hilst CS, Slooff MJ, Haagsma EB, et al. Nonanastomotic biliary strictures after liver transplantation, part 1: Radiological features and risk factors for early vs. late presentation. Liver Transpl 2007;13(5):708-18.

[89] Verdonk RC, Buis CI, van der Jagt EJ, Gouw AS, Limburg AJ, Slooff MJ, et al. Nonanastomotic biliary strictures after liver transplantation, part 2: Management, outcome, and risk factors for disease progression. Liver Transpl 2007;13(5):725-32.

[90] Guichelaar MM, Benson JT, Malinchoc M, Krom RA, Wiesner RH, Charlton MR. Risk factors for and clinical course of non-anastomotic biliary strictures after liver transplantation. Am J Transplant 2003;3(7):885-90.

[91] Ostroff JW. Post-transplant biliary problems. Gastrointest Endosc Clin N Am 2001;11(1):163-83.

[92] Zoepf T, Maldonado-Lopez EJ, Hilgard P, Malago M, Broelsch CE, Treichel U, et al. Balloon dilatation vs. balloon dilatation plus bile duct endoprostheses for treatment of anastomotic biliary strictures after liver transplantation. Liver Transpl 2006;12(1): 88-94. 
[93] Holt AP, Thorburn D, Mirza D, Gunson B, Wong T, Haydon G. A prospective study of standardized nonsurgical therapy in the management of biliary anastomotic strictures complicating liver transplantation. Transplantation 2007;84(7):857-63.

[94] Alazmi WM, Fogel EL, Watkins JL, McHenry L, Tector JA, Fridell J, et al. Recurrence rate of anastomotic biliary strictures in patients who have had previous successful endoscopic therapy for anastomotic narrowing after orthotopic liver transplantation. Endoscopy 2006;38(6):571-4.

[95] Kahaleh M, Behm B, Clarke BW, Brock A, Shami VM, De La Rue SA, et al. Temporary placement of covered self-expandable metal stents in benign biliary strictures: a new paradigm? (with video). Gastrointest Endosc 2008;67(3):446-54.

[96] Larghi A, Tringali A, Lecca PG, Giordano M, Costamagna G. Management of hilar biliary strictures. Am J Gastroenterol 2008;103(2):458-73.

[97] Wang AY, Ellen K, Berg CL, Schmitt TM, Kahaleh M. Fully covered self-expandable metallic stents in the management of complex biliary leaks: preliminary data - a case series. Endoscopy 2009;41(9):781-6.

[98] Sawyer RG, Punch JD. Incidence and management of biliary complications after 291 liver transplants following the introduction of transcystic stenting. Transplantation 1998;66(9):1201-7.

[99] Sheng R, Sammon JK, Zajko AB, Campbell WL. Bile leak after hepatic transplantation: cholangiographic features, prevalence, and clinical outcome. Radiology 1994;192(2):413-6.

[100] Barton P, Maier A, Steininger R, Muhlbacher F, Lechner G. Biliary sludge after liver transplantation: 1. Imaging findings and efficacy of various imaging procedures. AJR Am J Roentgenol 1995;164(4):859-64.

[101] Waldram R, Williams R, Calne RY. Bile composition and bile cast formation after transplantation of the liver in man. Transplantation 1975;19(5):382-7.

[102] Canete JJ, Aidlen JT, Uknis ME, Cicalese L. Images of interest. Hepatobiliary and pancreatic: biliary cast syndrome. J Gastroenterol Hepatol 2005;20(5):791.

[103] Shah JN, Haigh WG, Lee SP, Lucey MR, Brensinger CM, Kochman ML, et al. Biliary casts after orthotopic liver transplantation: clinical factors, treatment, biochemical analysis. Am J Gastroenterol 2003;98(8):1861-7.

[104] Freise CE, Gillespie BW, Koffron AJ, Lok AS, Pruett TL, Emond JC, et al. Recipient morbidity after living and deceased donor liver transplantation: findings from the A2ALL Retrospective Cohort Study. Am J Transplant 2008;8(12):2569-79.

[105] Shah SA, Grant DR, McGilvray ID, Greig PD, Selzner M, Lilly LB, et al. Biliary strictures in 130 consecutive right lobe living donor liver transplant recipients: results of a Western center. Am J Transplant 2007;7(1):161-7. 
[106] Gondolesi GE, Varotti G, Florman SS, Munoz L, Fishbein TM, Emre SH, et al. Biliary complications in 96 consecutive right lobe living donor transplant recipients. Transplantation 2004;77(12):1842-8.

[107] Hwang S, Lee SG, Sung KB, Park KM, Kim KH, Ahn CS, et al. Long-term incidence, risk factors, and management of biliary complications after adult living donor liver transplantation. Liver Transpl 2006;12(5):831-8.

[108] Soejima Y, Taketomi A, Yoshizumi T, Uchiyama H, Harada N, Ijichi H, et al. Biliary strictures in living donor liver transplantation: incidence, management, and technical evolution. Liver Transpl 2006;12(6):979-86.

[109] Seo JK, Ryu JK, Lee SH, Park JK, Yang KY, Kim YT, et al. Endoscopic treatment for biliary stricture after adult living donor liver transplantation. Liver Transpl 2009;15(4):369-80.

[110] Ghobrial RM, Freise CE, Trotter JF, Tong L, Ojo AO, Fair JH, et al. Donor morbidity after living donation for liver transplantation. Gastroenterology 2008;135(2):468-76.

[111] Hwang S, Lee SG, Joh JW, Suh KS, Kim DG. Liver transplantation for adult patients with hepatocellular carcinoma in Korea: comparison between cadaveric donor and living donor liver transplantations. Liver Transpl 2005;11(10):1265-72.

[112] Huang J. Ethical and legislative perspectives on liver transplantation in the People's Republic of China. Liver Transpl 2007;13(2):193-6.

[113] 113. Fung JJ, Eghtesad B, Patel-Tom K. Using livers from donation after cardiac death donors--a proposal to protect the true Achilles heel. Liver Transpl 2007;13(12):1633-6.

[114] Chen YK, Pleskow DK. SpyGlass single-operator peroral cholangiopancreatoscopy system for the diagnosis and therapy of bile-duct disorders: a clinical feasibility study (with video). Gastrointest Endosc 2007;65(6):832-41.

[115] Judah JR, Draganov PV. Intraductal biliary and pancreatic endoscopy: an expanding scope of possibility. World J Gastroenterol 2008;14(20):3129-36.

[116] Wright H, Sharma S, Gurakar A, Sebastian A, Kohli V, Jabbour N. Management of biliary stricture guided by the Spyglass Direct Visualization System in a liver transplant recipient: an innovative approach. Gastrointest Endosc 2008;67(7):1201-3.

[117] Atar E, Bachar GN, Bartal G, Mor E, Neyman H, Graif F, et al. Use of peripheral cutting balloon in the management of resistant benign ureteral and biliary strictures. J Vasc Interv Radiol 2005;16(2 Pt 1):241-5.

[118] 118. Silvis SE, Sievert CE, Jr., Vennes JA, Abeyta BK, Brennecke LH. Comparison of covered versus uncovered wire mesh stents in the canine biliary tract. Gastrointest Endosc 1994;40(1):17-21. 
[119] Ginsberg G, Cope C, Shah J, Martin T, Carty A, Habecker P, et al. In vivo evaluation of a new bioabsorbable self-expanding biliary stent. Gastrointest Endosc 2003;58(5): 777-84.

[120] Meng B, Wang J, Zhu N, Meng QY, Cui FZ, Xu YX. Study of biodegradable and selfexpandable PLLA helical biliary stent in vivo and in vitro. J Mater Sci Mater Med 2006;17(7):611-7. 
